DEMOGRAPHIC RESEARCH

VOLUME 39, ARTICLE 13, PAGES 381-414

PUBLISHED 5 SEPTEMBER 2018

https://www.demographic-research.org/Volumes/Vol39/13/

DOI: 10.4054/DemRes.2018.39.13

Research Article

Gender differences and similarities in the educational gradient in fertility: The role of earnings potential and gender composition in study disciplines

\title{
Alessandra Trimarchi
}

Jan Van Bavel

(C) 2018 Alessandra Trimarchi \& Jan Van Bavel.

This open-access work is published under the terms of the Creative Commons Attribution 3.0 Germany (CC BY 3.0 DE), which permits use, reproduction, and distribution in any medium, provided the original author(s) and source are given credit.

See https://creativecommons.org/licenses/by/3.0/de/legalcode. 


\section{Contents}

1 Introduction $\quad 382$

$2 \quad$ Education and fertility: Gender similarities and differences 383

$2.1 \quad$ Level of education 384

$2.2 \quad$ Field of study 385

2.3 Research hypotheses 386

$3 \quad$ Data and methods 387

3.1 Sample selection and dependent variable 387

3.2 Independent variables 389

$\begin{array}{lll}3.3 & \text { Analytical strategy } & 394\end{array}$

$4 \quad$ Results 394

4.1 Does the study discipline matter for fertility? 395

4.2 Which mechanisms link study discipline to men and women's 396

5 Discussion 402

$\begin{array}{lll}6 & \text { Acknowledgements } & 404\end{array}$

$\begin{array}{ll}\text { References } & 405\end{array}$

$\begin{array}{ll}\text { Appendix } & 410\end{array}$ 


\title{
Gender differences and similarities in the educational gradient in fertility: The role of earnings potential and gender composition in study disciplines
}

\author{
Alessandra Trimarchi ${ }^{1}$ \\ Jan Van Bavel ${ }^{2}$
}

\begin{abstract}
BACKGROUND

While women's participation in higher education has caught up with and surpassed that of men, large gender differences persist in the choice of field of study. To date, we know little about the mechanisms that explain the link between fertility and study disciplines for both men and women.
\end{abstract}

\section{OBJECTIVE}

To study gender differences in the effect on fertility of earnings potential and gender composition in study disciplines.

\section{METHODS}

We used European Labor Force Survey (EU-LFS) data and OLS models to estimate earnings potential. Next, we linked these estimates to the Generations and Gender Surveys (GGS) of six countries and applied piecewise linear hazard models to analyze the transition to first and second births jointly.

\section{RESULTS}

We found heterogeneity across countries, but within countries the mechanisms tend to be similar for both men and women.

\section{CONCLUSIONS}

This study suggests that the drivers of men's and women's family behavior may be more similar than is often expected. Societal changes that have occurred in the last three decades may lead to a stronger role for men in fertility decision-making, which may remain unnoticed if we continue to focus only on women.

\footnotetext{
${ }^{1}$ Institut National d'Études Démographiques (INED), Paris, France. Email: alessandra.trimarchi@ined.fr.

${ }^{2}$ Katholieke Universiteit Leuven, Belgium. Email: Jan.VanBavel@kuleuven.be.
} 


\section{CONTRIBUTION}

This study expands our knowledge of the relationship between men's education and fertility. It also broadens our understanding of the effect of the field of study on the fertility of both men and women by considering two characteristics of the study discipline: earnings potential and gender composition.

\section{Introduction}

In many Western and non-Western countries, in recent decades the number of highly educated women reaching reproductive ages has exceeded the number of highly educated men (Esteve, García-Román, and Permanyer 2012; Vincent-Lancrin 2008). While the gender gap in higher education has reversed, gender segregation with regard to the field of study has remained much more stable over time, reflecting inequalities in the labor market: i.e., ensuing differences concerning the earnings potential of men and women, given the same level of education (Blau and Khan 2016; Charles and Bradley 2009).

The level and the field of study may entail differential associations with fertility for men and women. Two economic mechanisms may explain the relationship between education and fertility: income effect and price effect (Becker 1991; Cigno 1991). The income effect is positive and accounts for the fact that the more-educated people tend to earn a higher income and therefore are more likely to be able to afford the monetary costs of children. The price effect is negative and acts through opportunity costs, because highly educated people lose more once they devote extra time to non-paid activities after becoming a parent. A model of the specialized gender division of labor within a household would predict opposite associations between education and fertility for men and women: The price effect characterizes the relationship between education and fertility for women, and the income effect for men (Becker 1991).

Recently, two theoretical approaches in family demography, namely the multiple equilibria framework and the Gender Revolution Theory, have emphasized the role of gender egalitarianism as an engine of fertility both in society at large and within households. Both frameworks have highlighted the fact that the negative relationship between education and women's fertility is weakening and in some contexts even turning positive (Esping-Andersen and Billari 2015; Goldscheider, Bernhardt, and Lappegård 2015). One reason for such a change may be that the earnings potential of highly educated women has become more important in their fertility decisions so that they show a positive income effect, while at the same time, as men engage more in raising children, the opportunity costs of parenthood become a more important factor 
for men (Huinink and Kohli 2014). This could lead to a weakening of the positive effect of men's education on fertility. However, evidence that could help to understand the mechanisms that link gender dynamics and fertility behaviors is lacking, since most work on education and fertility concerns women. If men are included at all it is typically in the context of their couple relationship (Trimarchi and Van Bavel 2017).

We aim to make a twofold substantive contribution to the literature. First, since the bulk of earlier work is on women's fertility, we aim to expand our knowledge of the relationship between men's education and fertility. Second, we broaden the understanding of the effect of the field of study on the fertility of both men and women by considering two characteristics of the study discipline: earnings potential and gender composition. Educational field is a distinctive trait of an individual's educational path, especially since the expansion of higher education (Cooney and Uhlenberg 1989). Next, since people decide on their field of study relatively early in their life course, it can be assumed to be less endogenous with respect to fertility than income earned around the time of childbearing, since childbearing and childbearing intentions are known to affect income. Endogeneity issues are especially problematic when detailed time-varying information on employment status, occupation, and income are not available (Xie et al. 2003). We therefore prefer to look at the earnings potential embodied in the educational degree obtained earlier in the life course rather than at actual current income.

We used data from the Generations and Gender surveys (1960-1987 cohorts) of Austria, Belgium, Bulgaria, Lithuania, Poland, and Romania. We estimated models for men and women separately by country, accounting for unobserved heterogeneity across birth episodes. The results show great heterogeneity across contexts, but the mechanisms tend to be similar for both men and women within contexts. We found that earnings potential is positively associated with men's second-birth rates (and to a lesser extent with women's) in Belgium, whereas a negative effect was found in other Central and Eastern European countries. Overall, the gender composition of the study field has a small effect on fertility rates.

\section{Education and fertility: Gender similarities and differences}

Scholars usually consider the impact of education on fertility as being 'multifaceted,' whilst specifically considering the following dimensions: enrollment, level, and field of study (Kravdal and Rindfuss 2008; Lappegård and Rønsen 2005). Here we focus on two dimensions: level of education and field of study. 


\subsection{Level of education}

Microeconomic theories predict that education and fertility have opposite associations for men and women (Cigno and Ermisch 1989; Becker 1991; Gustafsson 2001). Following the male-breadwinner model, the price effect is more characteristic of the relationship between education and fertility among women, since childbearing leads to a reduction of time spent in the paid labor market. The income effect - i.e., higher income making it possible to afford the monetary costs of having children predominates among men, since they are supposed to be the main breadwinners. A family model that is built on the specialization and gender division of labor presupposes compensatory roles for housework and paid work between partners, which is why opposite effects of education on fertility are expected for men and women.

Scholars have also highlighted mechanisms that are not necessarily specific to men or women. The income effect, usually considered positive, may turn null or even negative. This is because highly educated parents may want to invest more in their children and thus perceive raising an additional child as too expensive. However, highly educated people tend to have more resources (e.g., bigger social networks, financial means to outsource childcare and housework) and skills that can lower the opportunity costs of childbearing (Kravdal 2007). Moreover, a high level of education is also an important determinant of partnership rates. Highly educated men may be more attractive in the mating market and often they show higher union formation rates (Trimarchi and Van Bavel 2017); where the dual-earner model is established, highly educated women also become more attractive in the mating market (Oppenheimer 1994; Goldscheider, Bernhardt, and Lappegård 2015).

Several empirical studies have corroborated the positive association between men's fertility (in terms of total fertility rate and first-, second-, or third-birth timing) and level of education, in various contexts (Kravdal and Rindfuss 2008; Lappegård and Rønsen 2013; Nisén et al. 2014; Nisén et al. 2017; Tragaki and Bagavos 2014; WinklerDworak and Toulemon 2007). However, a negative effect of men's education has also been found for first-birth timing (Corijn and Klijzing 2001; Blossfeld et al. 2005; Martín-García 2009), which could be driven by the selection-into-union dynamic (Trimarchi and Van Bavel 2017). For women, the effect of educational level tends to be negative, particularly with regard to the first birth (Wood, Neels, and Kil 2014). In more recent cohorts the educational gradient in first-birth rates has been weakening in some countries (Wood, Neels, and Kil 2014; Goldscheider, Bernhardt, and Lappegård 2015). With regard to women's higher order births the effect of educational level is more puzzling. A positive effect on second and third births may be driven by selection into the transition to first birth (Kravdal 2001, 2007; Kreyenfeld 2002; Tesching 2012). Alternatively, the positive assortative mating between highly educated men and women, the so-called partner-effect, has been considered another reason for the observed 
positive effect of education on women's second births (Kreyenfeld 2002; Kreyenfeld and Konietzka 2008; Klesment et al. 2014), even if it has not been found in all studies (Gerster et al. 2007; Bartus et al. 2013).

\subsection{Field of study}

A growing strand of research focuses on the role of the field of study in order to understand the mechanisms that link education and fertility (Cooney and Uhlenberg 1989; Lappegård and Rønsen 2005; Hoem, Neyer, and Andersson 2006a, 2006b; Martín-García 2009; Van Bavel 2010; Lappegård, Rønsen, and Skrede 2011; Tesching 2012; Begall and Mills 2013; Oppermann 2014). In the literature the field of study has been considered because of its close affinity to an individual's future occupation (Ohlsson-Wijk 2015a). One economic feature of the field of study that scholars pinpoint is income potential (Lappegård and Rønsen 2005; Hoem, Neyer, and Andersson 2006a; Van Bavel 2010; Tesching 2012). Van Bavel (2010) measures the earnings profiles of different fields of study and finds that women who graduate in disciplines with higher earnings profiles tend to have a greater likelihood of postponing motherhood.

Next, the gender composition of the field of study may affect the socialization process both during the study period and in the (future) working environment. It could be that men and women who socialize with people of their own sex are more inclined towards gender-stereotypical parenting roles: "when there are many individuals of one's own sex there may be larger possibilities of doing gender" (Ohlsson-Wijk 2015b:12). Van Bavel (2010) shows that women who graduate in a study discipline that is characterized by strong (gender) stereotypical family attitudes are less likely to postpone motherhood. Several studies have corroborated the positive association between female-dominated fields and first-birth rates for women (Lappegård and Rønsen 2005; Martín-García and Baizan 2006; Van Bavel 2010; Tesching 2012; Begall and Mill 2013; Michelmore and Musick 2013), whereas mixed results have been found for higher order births and completed fertility (Hoem, Neyer, and Andersson 2006a; 2006b; Tesching 2012).

Much less is known about the effect of men's field of study. Data from Spain and Norway supports economic arguments that predict a positive relation between high earnings potential and fertility for men, assuming that male-dominated fields have higher earnings potential than female-dominated fields (Martín-García 2009; Lappegård, Rønsen, and Skrede 2011). These studies, however, do not directly account for the earnings potential of study disciplines, and thus the results may also be in line with the argument that socialization processes among people of one's own sex positively affect fertility. 
In this paper we focus on the role of earnings potential and the gender composition of the field of study. However, the relationship between field of study and fertility may be the result of self-selection processes. Individuals with aspirations, values, and preferences that are associated with large family size may be more inclined to opt for a field of study that is compatible with this ideal. According to Hakim's theory of preference, individuals adjust their life course to fit their lifestyle preferences and family values (Hakim 2003). In the literature this has been called the "anticipatory role" argument (Martín-García and Baizan 2006) or "family plan" thesis (Cech 2015), according to which women and men may self-select into a determined field of study because they foresee their role in the family or they already know their preferences concerning family formation processes. For instance, women who envisage becoming mothers would tend to choose a field of study that enhances the compatibility between family and work (Martín-García and Baizan 2006). Similarly, men who envisage becoming fathers would be more inclined to enroll in fields of study that allow them to have a secure job that can support the economic burden of children and related costs (Lappegård, Rønsen, and Skrede 2011). As a consequence, both the choice of discipline and the fertility quantum and timing may be the result of interrelated processes, a byproduct of preferences and personality traits (Hoem, Neyer, and Andersson 2006a; Tesching 2012; Oppermann 2014). Empirical findings for women have partially supported this proposition (Tesching 2012; Oppermann 2014), while results for men have not (Oppermann 2014; Martín-García 2009). The "anticipating role" argument has received some criticism, since empirical findings show that women's preference for female-dominated fields of study (or occupations) tends not to be rationally based on the labor market conditions that the fields of study/occupations offer (e.g., Cech 2015; Okamoto and England 1999).

\subsection{Research hypotheses}

Given the earlier research and theoretical arguments, our baseline expectation is that for both men and women, field of education is associated with fertility above and beyond the level of education. The main aim of this paper is to enhance our understanding of the mechanisms that link study discipline to fertility. More specifically, we test whether study discipline affects fertility via two mechanisms: earnings potential and gender composition of the study field.

We assume that individuals who graduate in disciplines with high income potential will be in a better position to sustain the economic burden of children. However, higher earnings potential may also entail higher opportunity costs, as a result of time investments in childrearing. Our first hypothesis is based on the consideration that 
income effects have tended to predominate for men while opportunity costs have been more important for women. We therefore expect a positive effect of earnings potential on men's fertility (H1a) and a negative effect on women's fertility (H1b).

Hypothesis 2 concerns the role of gender composition in the field of study and the ensuing socialization processes. This hypothesis is based on the assumption that individuals who graduate in disciplines with a higher share of their own sex will (self) reinforce gender-stereotypical behaviors that are normatively expected from a woman and a man within a couple. We expect that men who graduate in stereotypical masculine disciplines have higher fertility than men who graduate in female-dominated fields (H2a). Similarly, we expect that women who graduate in female-dominated fields have higher fertility than women who graduate in male-dominated fields (H2b).

\section{Data and methods}

\subsection{Sample selection and dependent variables}

To test our hypotheses we applied event history analyses for the transition to first and second births to the Generations and Gender Surveys (GGS) of six European countries that collected suitable information on the field of study. These countries are Austria, Belgium, Bulgaria, Lithuania, Poland, and Romania. We focused on respondents born between 1960 and 1987, distinguishing three birth cohorts in our models: 1960-1969, 1970-1979, and 1980-1987. From an initial sample of 34,647 respondents we dropped individuals with missing information on the level of education $(n=50)$ and respondents who did not attain an upper secondary level of education $(n=5,291)$. We made this selection because the focus of the paper is the role of the study discipline, which is applicable only when individuals reached at least an upper secondary level of education.

In this study we examine the effect of the educational field, rather than enrollment in education. As a consequence, our observation period starts at time of completion of the highest level of education attained, whatever the level of education. With regard to first birth, the process time is the time spent since graduation until the conception of the first child (if that occurred), censoring (age 45), or interview, whichever came first. We used the information on the month and year of births; if the month was missing, we randomly imputed it. The end of enrollment was based on the time of graduation as reported by the respondent $(95.75 \%)$. If the information on graduation was missing we based it on the standard age at graduation for the specific level of education and country (4.25\% of the cases). For respondents attaining a tertiary level of education, where the study duration tends to be most variable, this percentage was only $0.39 \%$. We checked 
the robustness of our models against these assumptions by dropping the $4.25 \%$ with missing information on the actual age at graduation; the results were not affected.

We dropped cases for which the age at graduation was negative or low, relative to the level of education attained $(n=337){ }^{3}$ Next, we dropped respondents with missing information on the time to first birth $(\mathrm{n}=23)$ or if the conception of the child occurred before obtaining the degree $(\mathrm{n}=3,956)$; the proportion of cases deleted for the latter reason varied by country. In most of the countries it was below $9 \%$, with the exception of Bulgaria (almost 14\%), Poland (17\%), and Lithuania (24\%). Using age 15 as the start of the observational period would strongly limit sample selection given that only 55 respondents would have been deleted. However, we were concerned that our analysis would reflect reverse causality when the observation started at age 15 instead of time of completion of the highest level of education attained. Individuals who become parents before finishing their intended education may adjust their educational goals (i.e., level of education and chosen field of study) so that they are compatible with the newly acquired parental role. This has been shown to hold especially for women (MartínGarcía and Baizan 2006; Tesching 2012; Oppermann 2014). To limit the problem of reverse causality we use age at graduation as the starting observational point in this study. Additionally, we cannot assess precisely when the individual was enrolled in education because the complete educational history of the respondents is not available. Note, finally, that our focus is on field of study, which is fixed after graduation to the extent that we observe the final degree our respondents have ever obtained.

However, we ran analyses using as time process the time since 15 years old, including enrolment in education as a control variable. As expected, the negative educational gradient in first births is steeper than when using time since graduation as process in time. In Central and Eastern European countries the parameters concerning the role of educational level tend to be especially affected with regard to the transition to motherhood. We found that the sample selection is more strongly altered for the women in those countries.

Finally, 27 respondents were dropped by default because they reported an age at completion of education higher than 45 , which was our censoring time. ${ }^{4}$ After all the selections mentioned, the sample totaled 24,963 respondents $-11,915$ males and 13,048 females. With regard to second births, the time process is given by the time elapsed since first birth until the next conception, or until censoring either after 15 years or at interview time. The respondents at risk of having a second child were those who had a first child; thus we dropped the respondents who did not have a first child during our

\footnotetext{
${ }^{3}$ We dropped cases if: the reported age at graduation was negative $(n=19)$; if the individual reported an upper secondary level before age $14(\mathrm{n}=117)$; and if the individual reported a tertiary level of education before age $20(n=201)$.

${ }^{4}$ Results were not affected if we increased the age at censoring.
} 
observational period $(\mathrm{n}=10,321)$. Next, we dropped respondents with an invalid time to event for survival analysis $(\mathrm{n}=74)$. For the second-birth analysis the sample totaled 14,568 individuals, 6,233 males and 8,335 females.

\subsection{Independent variables}

The main independent variables are earnings potential and the share of women within a study discipline. Earnings potential is based on the educational degree of the respondent according to the field of study of the highest educational level of attainment. We grouped respondents into two levels of education (medium, high), collapsing categories from the International Standard Classification of Education (ISCED 1997). The medium category consists of respondents who completed upper secondary and postsecondary levels (ISCED 3 and 4). The highly educated respondents are those with a bachelor/master/PhD degree (ISCED 5 and 6).

The field of study variable in the GGS was collected as an open question and refers to the main discipline of the highest level of education attained. As we needed to have a variable compatible with the European Labor Force Surveys (EU-LFS), to harmonize the categories across countries and across surveys we followed the UNESCO/ISCED-F[2013] indications for the field of study. We constructed a variable consisting of eight discipline categories: (1) general/unspecified field, (2) humanities and arts, (3) social sciences/business/law, (4) science and technology, (5) agriculture, (6) health and welfare, (7) education, and (8) services. As shown in Table 1 and Table 2 , the distribution of this variable is sometimes peculiar. For instance, in Belgium the share of men graduating in Humanities and Arts is almost similar to the share of men graduating in Science and Technology. After a deeper inspection of the data it turns out that the majority of men graduating in Humanities and Arts are medium-educated and hold an occupation related to technological fields. Thus, it is likely that these men have declared the track that they chose for their upper secondary level degree rather than their subsequent field of specialization, which could have been more vocationally oriented. Next, in Romania the participation of women in Science and Technology is almost double that of other countries. This outcome is consistent with findings from other studies: Romania is among the countries where women earn the largest share of science degrees compared with other countries (Charles 2011; Charles and Bradley 2009). This is probably linked to the fact that in some Central and Eastern European countries, under the communist regimes both boys and girls were required to study math and science throughout secondary school (Charles and Bradley 2009: 963).

${ }^{5}$ http://www.uis.unesco.org/Education/Pages/international-standard-classification-of-education.aspx accessed the $14^{\text {th }}$ September 2015. 
Next, we measured earnings potential, i.e., the latent, unobserved capacity to earn an income (Xie et al. 2003: 356). We used the 2009-2013 EU-LFS of the six countries in our sample and estimated earnings potential by means of OLS regressions. The dependent variable of our OLS regressions is the respondents' income deciles (information already given within the survey), which was only gathered for those who declared being employed in the reference week of interview. We estimated earnings potential based on a sample of full- and part-time working people aged 20-64, following the equation:

$$
\begin{aligned}
y_{(\text {income deciles })=}= & +\beta_{1}(\text { age })+\beta_{2}\left(\text { age }^{2}\right) \\
& +\beta_{3}(\text { years since start current work })+\beta_{4}(\text { survey year }) \\
& +\beta_{5}(\text { educational level } * \text { field of study }) \\
& +\beta_{6}(\text { part }- \text { time })+\varepsilon .
\end{aligned}
$$

The value of interest to us is the regression coefficient $\beta_{5}$, which is estimated separately for each country and sex. This regression coefficient refers to the relative difference in the expected income deciles, given a certain level of education and study discipline ${ }^{6}$ (results of these estimations are showed in Figure A-1 and Figure A-2 in the Appendix). As a robustness check we also estimated earnings potential based on a sample of full-time working people only; our conclusions remained substantially similar (results available upon request). Though we included a proxy for work experience, and despite the robustness checks, it could still be that fields of study with low earnings potential are over-represented among women with more children. Higher fertility may lead to lower accumulated work-experience and thus to a lower income. In general, this measure of earnings potential aims to catch the relative difference by level of education and field of study in the capacity to earn an income. It should not be interpreted as a measure of the changes over time in the expected income level.

Next, to obtain the share of women within a field by country and across levels of education, we further used the joint UNESCO/OECD/Eurostat database on education. Eurostat has time series from 1998 until 2012 for the absolute numbers of graduates in each field of study, excluding the 'general/unspecified' field. ${ }^{7}$ We extracted the number of females and the total number of graduates for each field and country from the Eurostat database, pooling data from level 3 to 6 of the ISCED 1997 classification. The

\footnotetext{
${ }^{6}$ In Lithuania and Romania, due to the lack of observations, it was not possible to estimate the earnings potential of highly educated men and women in the general/unspecified category. As a consequence, in the models that estimate birth transitions using GGS data we dropped these individuals. Overall, in Lithuania we had to drop three men and two women, and in Romania 22 men and 6 women.

${ }^{7}$ Since Eurostat does not provide information on the general/unspecified field of study, we calculated the proportion of women in this category using the GGS data, considering all men and women born from 19601987 with at least an upper secondary degree.
} 
share of women within the field was averaged across years (see Figure.1), and it was included in the models as a continuous variable. By including the share of women by field of study we could partially account for values that are not necessarily associated with the economic aspects of an educational degree.

The effect of education on childbearing is related to the effect of education on union formation and partner's characteristics. This is why we also ran models that accounted for a time-varying variable that indicated whether the respondent was in a union or not. If the respondent was in a union, we distinguished between those partnered with a low-, medium-, or highly educated partner. We added a category, "not available," to account for individuals in union but with missing information about the partner's education. We additionally included both the father's and the mother's educational attainment and the number of the respondent's siblings, since all these family background variables are relevant to individuals' childbearing behavior (Rindfuss, Morgan, and Swicegood 1988). With regard to the transition to first birth, we controlled for age at graduation and its square, whereas for the transition to second birth we controlled for age at first birth and its square.

\section{Figure 1: Share of graduated women (ISCED 3 to 6) by field of study and country 1998-2012}

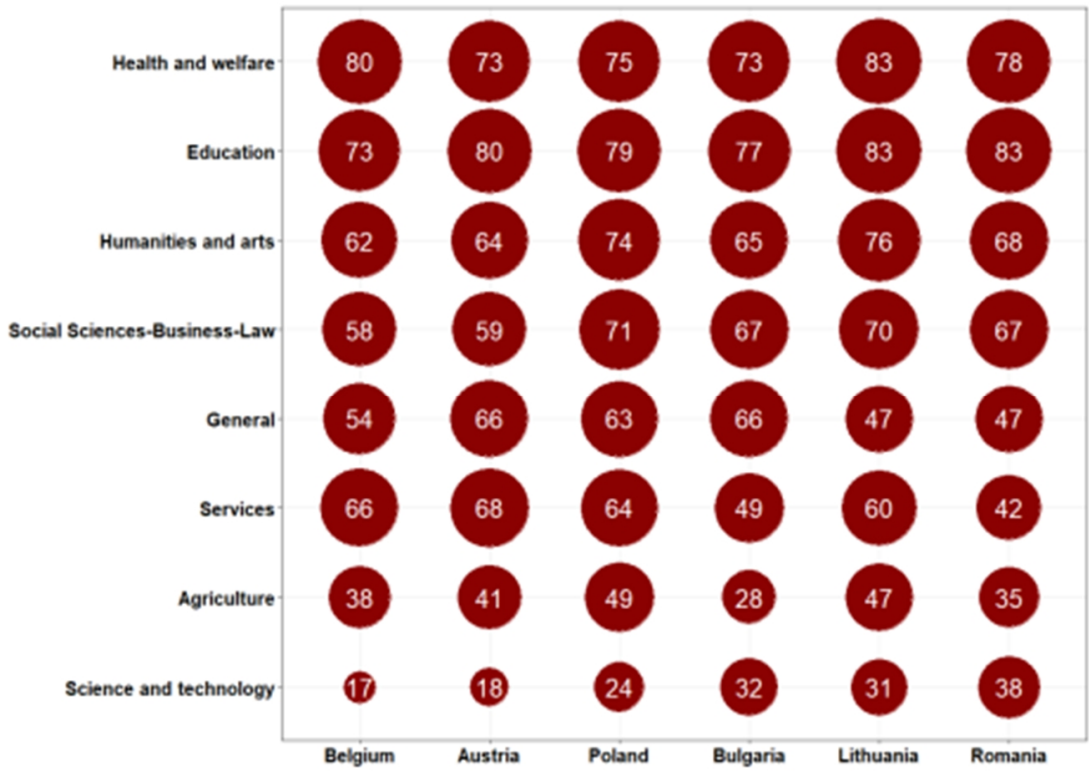

Source: Own calculations based on the UNESCO/OECD/Eurostat database on education [educ_grad5]. 
Trimarchi \& Van Bavel: Gender differences and similarities in the educational gradient in fertility

Table 1: Descriptive statistics (percentages and means) for the male sample, by country

\begin{tabular}{|c|c|c|c|c|c|c|}
\hline & Austria & Belgium & Bulgaria & Lithuania & Poland & Romania \\
\hline \multicolumn{7}{|l|}{ Cohort (\%) } \\
\hline 1960-1969 & 30.93 & 38.4 & 37.24 & 37.44 & 31.16 & 43.29 \\
\hline 1970-1979 & 39.25 & 35.48 & 38.98 & 34.7 & 37.65 & 37.87 \\
\hline $1980-1987$ & 29.82 & 26.12 & 23.78 & 27.86 & 31.19 & 18.84 \\
\hline \multicolumn{7}{|l|}{ Mother's education (\%) } \\
\hline Low & 44.76 & 42.64 & 30.99 & 29.23 & 29.81 & 62.38 \\
\hline Medium & 44.43 & 26.85 & 50 & 45.7 & 55.21 & 30.74 \\
\hline High & 5.96 & 23.76 & 15.76 & 15.73 & 10.06 & 4.62 \\
\hline NA & 4.85 & 6.75 & 3.26 & 9.34 & 4.92 & 2.26 \\
\hline \multicolumn{7}{|l|}{ Father's education (\%) } \\
\hline Low & 24.18 & 33.28 & 31.47 & 32.08 & 23.05 & 44.1 \\
\hline Medium & 58.19 & 28.07 & 48.05 & 34.13 & 56.5 & 41.69 \\
\hline High & 6.82 & 27.01 & 12.24 & 11.91 & 9.81 & 6.68 \\
\hline NA & 10.81 & 11.64 & 8.25 & 21.88 & 10.64 & 7.53 \\
\hline \multicolumn{7}{|l|}{ Siblings (\%) } \\
\hline No sib & 11.14 & 10.09 & 14.84 & 17.38 & 8.78 & 16.98 \\
\hline $1 \mathrm{sib}$ & 32.83 & 34.66 & 64.67 & 46.15 & 33.22 & 36.01 \\
\hline $2 \mathrm{sib}$ & 24.44 & 24.74 & 10.72 & 20.74 & 25.24 & 22.35 \\
\hline $3+$ & 31.59 & 30.51 & 9.77 & 15.73 & 32.77 & 24.66 \\
\hline \multicolumn{7}{|l|}{ Respondent's education (\%) } \\
\hline Medium & 82.44 & 51.02 & 86.37 & 78.01 & 75.76 & 86.89 \\
\hline High & 17.56 & 48.98 & 13.63 & 21.99 & 24.24 & 13.11 \\
\hline \multicolumn{7}{|l|}{ Respondent's field of study (\%) } \\
\hline General & 9.17 & 24.82 & 14.41 & 30.94 & 8.81 & 9.64 \\
\hline Humanities and Arts & 1.9 & 22.7 & 1.43 & 2.11 & 1.74 & 0.3 \\
\hline Social Sciences-Business-Law & 17.04 & 16.52 & 7.2 & 8.55 & 12.25 & 2.51 \\
\hline Science and Technology & 57.27 & 23.84 & 53.3 & 40.85 & 61.19 & 67.25 \\
\hline Agriculture & 6.23 & 2.12 & 5.99 & 6.95 & 6.66 & 6.98 \\
\hline Health and Welfare & 1.51 & 6.27 & 2.34 & 0.68 & 1.29 & 3.21 \\
\hline Education & 0.52 & 3.5 & 0.65 & 2.11 & 1.41 & 9.09 \\
\hline Services & 6.36 & 0.24 & 14.67 & 7.81 & 6.66 & 1 \\
\hline Age at graduation (median) & 19.17 & 21 & 18.33 & 20.31 & 19.58 & 18.58 \\
\hline Age at first birth (median) & 27.75 & 29.08 & 25.17 & 25.42 & 26.25 & 25.67 \\
\hline $\mathrm{N} 1^{\text {st }}$ births & 703 & 633 & 1058 & 882 & 1872 & 1114 \\
\hline $\mathrm{N} 2^{\text {nd }}$ births & 423 & 433 & 519 & 464 & 1118 & 521 \\
\hline $\mathrm{N}$ & 1526 & 1229 & 2304 & 1755 & 3110 & 1991 \\
\hline
\end{tabular}

Source: own calculations based on GGS data. 
Table 2: Descriptive statistics (percentages and means) for the female sample, by country

\begin{tabular}{|c|c|c|c|c|c|c|}
\hline & Austria & Belgium & Bulgaria & Lithuania & Poland & Romania \\
\hline \multicolumn{7}{|l|}{ Cohort (\%) } \\
\hline 1960-1969 & 29.15 & 36.79 & 37.02 & 42.98 & 31.33 & 41.08 \\
\hline 1970-1979 & 40.92 & 36.16 & 40.03 & 32.25 & 37.76 & 39.67 \\
\hline 1980-1987 & 29.93 & 27.05 & 22.95 & 24.77 & 30.91 & 19.25 \\
\hline \multicolumn{7}{|l|}{ Mother's education (\%) } \\
\hline Low & 41.01 & 38.53 & 29.71 & 34.37 & 32.7 & 60.66 \\
\hline Medium & 48.51 & 31.02 & 50.96 & 44.04 & 55.44 & 31.94 \\
\hline High & 6.94 & 22.25 & 16.61 & 14.35 & 7.76 & 4.83 \\
\hline NA & 3.54 & 8.21 & 2.71 & 7.24 & 4.09 & 2.58 \\
\hline \multicolumn{7}{|l|}{ Father's education (\%) } \\
\hline Low & 22.34 & 32.61 & 28.81 & 34.19 & 25.42 & 42.56 \\
\hline Medium & 57.75 & 26.22 & 48.64 & 32.63 & 56.61 & 44.11 \\
\hline High & 9.38 & 25.94 & 13.25 & 10.92 & 6.91 & 6.89 \\
\hline NA & 10.53 & 15.23 & 9.3 & 22.27 & 11.06 & 6.44 \\
\hline \multicolumn{7}{|l|}{ Siblings (\%) } \\
\hline No sib & 8.28 & 10.5 & 14.59 & 15.22 & 8.44 & 15.9 \\
\hline $1 \mathrm{sib}$ & 33.93 & 33.66 & 64.17 & 45.85 & 30.54 & 37.93 \\
\hline $2 \mathrm{sib}$ & 27.4 & 25.66 & 11.51 & 22.52 & 24.28 & 22.73 \\
\hline $3+$ & 30.39 & 30.18 & 9.74 & 16.41 & 36.74 & 23.44 \\
\hline \multicolumn{7}{|l|}{ Respondent's education (\%) } \\
\hline Medium & 79.72 & 45.13 & 76.73 & 71.68 & 70.03 & 86.09 \\
\hline High & 20.28 & 54.87 & 23.27 & 28.32 & 29.97 & 13.91 \\
\hline \multicolumn{7}{|l|}{ Respondent's field of study (\%) } \\
\hline General & 12 & 24.48 & 21.9 & 26.51 & 12.03 & 10.88 \\
\hline Humanities and Arts & 4.46 & 10.15 & 3.51 & 4.93 & 4.21 & 3.35 \\
\hline Social Sciences-Business-Law & 38.3 & 10.22 & 17.34 & 21.83 & 29.51 & 4.19 \\
\hline Science and Technology & 8.51 & 22.74 & 32.43 & 20.65 & 24.37 & 58.79 \\
\hline Agriculture & 1.93 & 9.6 & 2.75 & 3.81 & 6.45 & 8.31 \\
\hline Health and Welfare & 9.84 & 14.74 & 7.17 & 7.24 & 5.8 & 10.43 \\
\hline Education & 6.76 & 7.93 & 3.8 & 9.36 & 5.2 & 2.38 \\
\hline Services & 18.21 & 0.14 & 11.11 & 5.68 & 12.43 & 1.67 \\
\hline Age at graduation (median) & 19.25 & 21.17 & 18.42 & 20.31 & 19.67 & 18.67 \\
\hline Age at first birth (median) & 26 & 27.08 & 22.17 & 24.12 & 23.92 & 23.5 \\
\hline $\mathrm{N} 1^{\text {st }}$ births & 1256 & 914 & 1693 & 978 & 2511 & 1029 \\
\hline$N 2^{\text {nd }}$ births & 837 & 599 & 874 & 507 & 1561 & 476 \\
\hline $\mathrm{N}$ & 2175 & 1438 & 2763 & 1603 & 3517 & 1553 \\
\hline
\end{tabular}

Source: own calculations based on GGS data. 


\subsection{Analytical strategy}

We applied piecewise linear hazard models to estimate the effect of educational characteristics on first- and second-birth rates, separately for men and women, estimated using the aML software (Lillard and Panis 2003). When studying the effect of education on second births it is important to account for the selection into parenthood (Kravdal 2001, 2007; Kreyenfeld 2002). Following Kravdal (2001), we controlled for the selectivity into parenthood by modeling birth episodes jointly, where births are nested within individuals. This modeling approach accounts for a random effect that represents common unobserved factors across birth episodes. Although the focus of this paper is on the transition to first and second births, we included in our system of equations the transition to third birth to better estimate the random effect. The system of equations can be formally displayed as follows:

$$
\begin{aligned}
& \ln h(t)^{1}=\gamma^{\prime} T(t)+\beta^{\prime} X(t)+\varepsilon \\
& \ln h(t)^{2}=\gamma^{\prime} T(t)+\beta^{\prime} X(t)+\varepsilon \\
& \ln h(t)^{3}=\gamma^{\prime} T(t)+\beta^{\prime} X(t)+\varepsilon
\end{aligned}
$$

The superscripts 1,2, and 3 refer to the equations for the first, second, and third birth respectively, and $\ln h(t)$ is the log-hazard of occurrence at time $t$. In the equation for first birth, $\gamma^{\prime} T(t)$ is a piecewise linear transformation of time since graduation, with nodes at 2, 4, 6, 10, and 15 years. For the second and third birth, $\gamma^{\prime} T(t)$ is a piecewise linear transformation of time since previous birth, with nodes at 2, 4, 6, and 11 years. The covariate profile (for both fixed and time-varying covariates) is given by $\beta^{\prime} X(t)$, which shifts the baseline hazard up or down. The random variable $\varepsilon$ represents an unobserved factor, which is assumed to be normally distributed with mean 0 and variance $\sigma^{2}$ to be estimated. In our models the distribution of $\varepsilon$ is approximated by ten integration points. Estimating separate models for each birth transition would exclude $\varepsilon$ in each equation, yielding biased estimates. The unobserved factors at the individual level can represent several things, including physical attractiveness or fecundity. Note that the joint model for women's birth rates in Romania did not converge due to relatively fewer second- and third-birth episodes; thus we present the results that do not include the random effect. All models were estimated separately by country and sex.

\section{Results}

First, we test to what extent the field of study matters for men's and women's transitions to first and second births. In the second part we report the results of the 
models, which provide insight into the mechanisms that link the characteristics of the study disciplines to fertility.

\subsection{Does the study discipline matter for fertility?}

Figures 2 and 3 show the estimates with 95\% confidence intervals of the categorical variable of the study discipline for the transition to first and second births. To test whether the model fit improves with the introduction of the study discipline we used a log-likelihood ratio test. The models also control for time since graduation, or time since previous birth in the case of second births; birth cohort; age at graduation (or age at first birth) and its square; educational attainment of respondent's parents; respondent's number of siblings; and respondent's educational attainment.

Figure 2: Model estimates of the study discipline for the transition to men's first and second births (reference category: men graduated in Science and Technology)

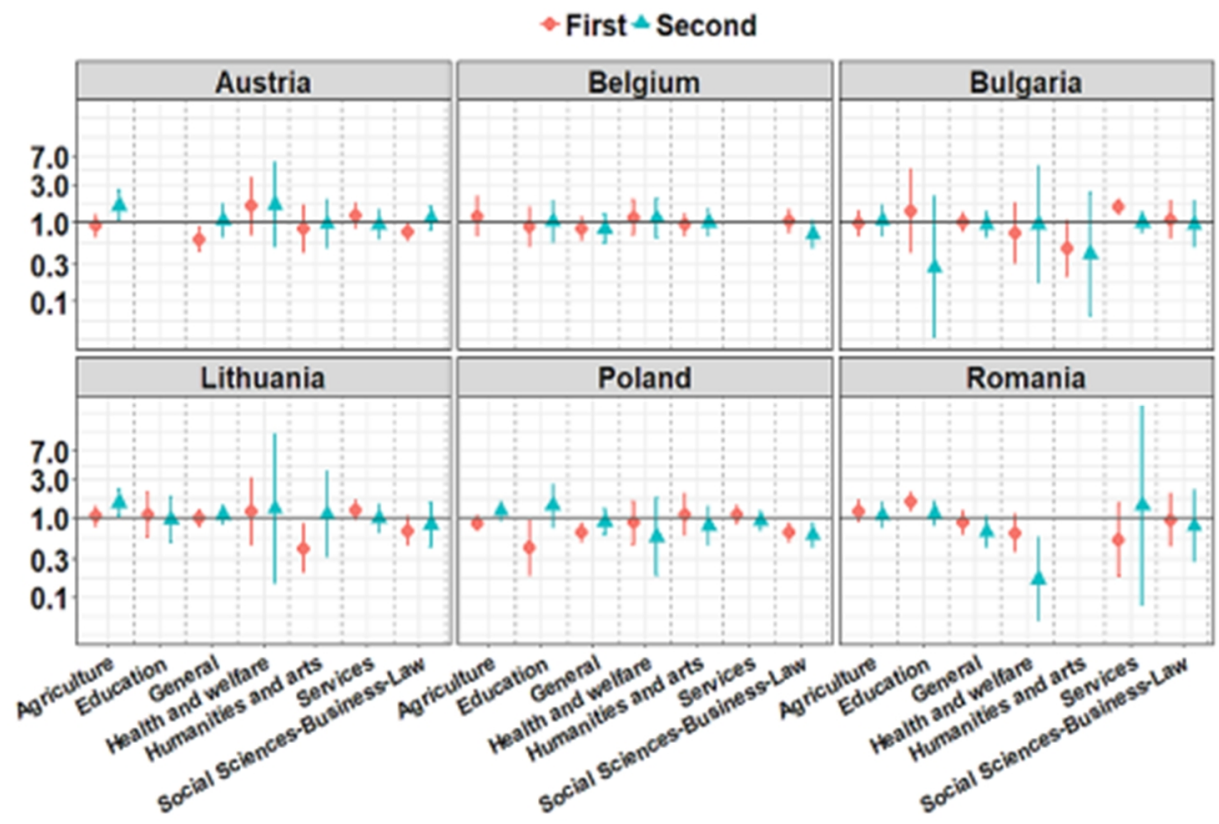


Figure 3: Model estimates of the study discipline for the transition to women's first and second births (reference category: women graduated in Science and Technology)

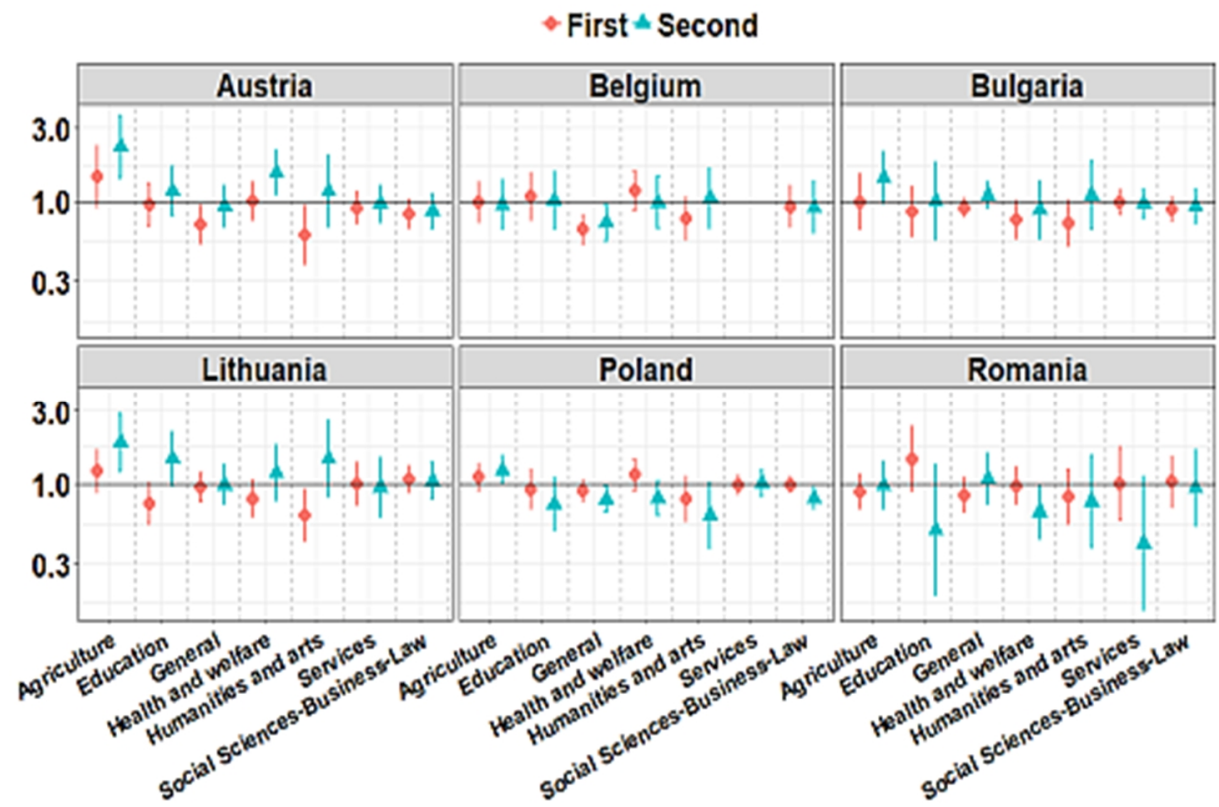

Source: Own calculations on GGS data.

We found that when adding the study disciplines the model fit significantly improves $(p<0.05)$ for the sample of men in Bulgaria, Poland, and Romania, and to a lesser extent $(p<0.1)$ for Lithuania. For the sample of women we found that the study discipline significantly improves $(p<0.05)$ the model fit in Austria, Belgium, Lithuania, and Poland. In sum, not in all contexts does the field of study matter relatively more than educational level. It appears that in countries where the field of study is relatively important for men's fertility, it is not so for women's fertility. The only exception to this pattern is Poland. 


\subsection{Which mechanisms link study discipline to men and women's fertility?}

We proposed two mechanisms to explain the link between study discipline and fertility. The first concerns the role of earnings potential by field and level of education. The second mechanism works through the gender composition of the study discipline. We present four models for the transition to first and second births. In the first model (M1) we assess the effect of earnings potential, while in the second model (M2) we also account for the gender composition of the study discipline. Next, we include union status in model three (M3), and in the fourth model (M4) we account for partner's educational level. Overall, the effects of the control variables tend to be in line with expectations; however, we only discuss the variables of major interest (Table A-1 and Table A-2 of the Appendix show the effects of control variables in the full model, M4, for men and women respectively).

Table 3 presents the results for the male sample, separately by country and birth parity. Overall, we did not find consistent support for our hypothesis (H1a) according to which men's earnings potential is positively associated with fertility rates due to an income effect. Instead, our results show variation across countries and birth parity. We did not find any effect of earnings potential regarding the transition to fatherhood, except in Poland, where it has a statistically significant negative effect. Next, we found that earnings potential is positively associated with men's second-birth rates in Belgium, whereas it is negatively associated in other countries, with the strongest negative effects in Bulgaria and Romania.

According to our second hypothesis, study disciplines with a higher share of one's own sex enhance fertility due to socialization processes that reinforce genderstereotypical behaviors. We found that in the considered contexts the gender composition of the study discipline is more relevant to understanding the transition to first birth rather than second birth. A higher share of women within the study discipline is negatively associated with men's transition to fatherhood in Poland, in line with our hypothesis $\mathrm{H} 2 \mathrm{a}$, whereas in Romania it is positively associated with men's first-birth rates.

When we control for partnership status (M3) it is noticeable that the significance and direction of the effect of the gender composition variable tend to change in the majority of contexts and with regard to the transition to fatherhood. Next, once we account for partners' educational level (M4), the positive effect of earnings potential in Belgium on men's second-birth rates is reduced, whereas in other Central and Eastern European countries it is no longer statistically significant. 
Trimarchi \& Van Bavel: Gender differences and similarities in the educational gradient in fertility

Table 3: Model estimates for the transition to first and second births, male sample

\begin{tabular}{|c|c|c|c|c|c|c|c|c|}
\hline & First & & & & Second & & & \\
\hline Austria & M1 & M2 & M3 & M4 & M1 & M2 & M3 & M4 \\
\hline \multirow[t]{2}{*}{ Earnings potential } & -0.03 & -0.02 & 0.07 & 0.09 & 0.00 & 0.00 & -0.01 & -0.03 \\
\hline & $(0.09)$ & $(0.09)$ & $(0.10)$ & $(0.10)$ & $(0.11)$ & $(0.11)$ & $(0.11)$ & $(0.12)$ \\
\hline \multirow[t]{2}{*}{ Share of women } & & 0.00 & -0.01 & 0.00 & & 0.00 & 0.00 & 0.00 \\
\hline & & $(0.00)$ & $(0.00)$ & $(0.00)$ & & $(0.00)$ & $(0.00)$ & $(0.00)$ \\
\hline \multirow[t]{2}{*}{ In union (Ref=Not in union) } & & & 2.34 & & & & 1.91 & \\
\hline & & & $(0.11)$ & & & & $(0.31)$ & \\
\hline \multicolumn{9}{|c|}{ Partner's education (Ref=Not in union) } \\
\hline \multirow[t]{2}{*}{ Low education partner } & & & & 2.69 & & & & 1.99 \\
\hline & & & & $(0.19)$ & & & & $(0.34)$ \\
\hline \multirow[t]{2}{*}{ Medium education partner } & & & & 2.33 & & & & 1.90 \\
\hline & & & & $(0.12)$ & & & & $(0.31)$ \\
\hline \multirow[t]{2}{*}{ Higher education partner } & & & & 2.14 & & & & 2.12 \\
\hline & & & & $(0.17)$ & & & & $(0.36)$ \\
\hline \multicolumn{2}{|l|}{ NA education partner } & & & 0.00 & & & & 0.00 \\
\hline Belgium & M1 & M2 & M3 & M4 & M1 & M2 & M3 & M4 \\
\hline \multirow[t]{2}{*}{ Earnings potential } & 0.11 & 0.11 & 0.06 & -0.02 & 0.17 & 0.17 & 0.20 & 0.08 \\
\hline & $(0.08)$ & $(0.08)$ & $(0.07)$ & $(0.07)$ & $(0.07)$ & $(0.08)$ & $(0.07)$ & $(0.08)$ \\
\hline \multirow[t]{2}{*}{ Share of women } & & 0.00 & 0.00 & 0.00 & & 0.00 & 0.00 & 0.00 \\
\hline & & $(0.00)$ & $(0.00)$ & $(0.00)$ & & $(0.00)$ & $(0.00)$ & $(0.00)$ \\
\hline \multirow[t]{2}{*}{ In union (Ref=Not in union) } & & & 3.02 & & & & 2.26 & \\
\hline & & & $(0.17)$ & & & & $(0.49)$ & \\
\hline \multicolumn{9}{|c|}{ Partner's education (Ref=Not in union) } \\
\hline \multirow[t]{2}{*}{ Low education partner } & & & & 3.15 & & & & 1.93 \\
\hline & & & & $(0.25)$ & & & & $(0.52)$ \\
\hline \multirow[t]{2}{*}{ Medium education partner } & & & & 3.36 & & & & 2.19 \\
\hline & & & & $(0.18)$ & & & & $(0.51)$ \\
\hline \multirow[t]{2}{*}{ Higher education partner } & & & & 3.42 & & & & 2.70 \\
\hline & & & & $(0.17)$ & & & & $(0.52)$ \\
\hline \multirow[t]{2}{*}{ NA education partner } & & & & 1.77 & & & & 1.42 \\
\hline & & & & $(0.20)$ & & & & $(0.51)$ \\
\hline Bulgaria & M1 & M2 & M3 & M4 & M1 & M2 & M3 & M4 \\
\hline \multirow[t]{2}{*}{ Earnings potential } & -0.06 & -0.07 & -0.22 & -0.22 & -0.38 & -0.37 & -0.28 & -0.22 \\
\hline & $(0.12)$ & $(0.12)$ & $(0.12)$ & $(0.12)$ & $(0.13)$ & $(0.13)$ & $(0.11)$ & $(0.12)$ \\
\hline \multirow[t]{2}{*}{ Share of women } & & 0.00 & 0.01 & 0.01 & & 0.00 & 0.00 & 0.00 \\
\hline & & $(0.00)$ & $(0.00)$ & $(0.00)$ & & $(0.00)$ & $(0.00)$ & $(0.00)$ \\
\hline \multirow[t]{2}{*}{ In union (Ref=Not in union) } & & & 3.61 & & & & 1.49 & \\
\hline & & & $(0.09)$ & & & & $(0.39)$ & \\
\hline \multicolumn{9}{|c|}{ Partner's education (Ref=Not in union) } \\
\hline \multirow[t]{2}{*}{ Low education partner } & & & & 3.25 & & & & 1.73 \\
\hline & & & & $(0.20)$ & & & & $(0.43)$ \\
\hline Medium education partner & & & & 3.69 & & & & 1.50 \\
\hline & & & & $(0.09)$ & & & & $(0.39)$ \\
\hline Higher education partner & & & & 3.61 & & & & 1.32 \\
\hline & & & & $(0.14)$ & & & & $(0.41)$ \\
\hline NA education partner & & & & 2.45 & & & & 0.86 \\
\hline & & & & $(0.55)$ & & & & $(1.11)$ \\
\hline
\end{tabular}


Table 3: (Continued)

\begin{tabular}{|c|c|c|c|c|c|c|c|c|}
\hline & First & & & & Seconc & & & \\
\hline Lithuania & M1 & M2 & M3 & M4 & M1 & M2 & M3 & M4 \\
\hline Earnings potential & 0.09 & 0.09 & -0.04 & -0.04 & -0.03 & -0.03 & -0.08 & -0.05 \\
\hline & $(0.09)$ & $(0.09)$ & $(0.09)$ & $(0.09)$ & $(0.10)$ & $(0.10)$ & $(0.10)$ & $(0.10)$ \\
\hline Share of women & & 0.00 & -0.01 & -0.01 & & 0.00 & 0.00 & 0.00 \\
\hline & & $(0.00)$ & $(0.00)$ & $(0.00)$ & & $(0.00)$ & $(0.00)$ & $(0.00)$ \\
\hline In union (Ref=Not in union) & & & 2.63 & & & & 1.11 & \\
\hline & & & $(0.09)$ & & & & $(0.35)$ & \\
\hline Partner's education $(\mathrm{Ref}=\mathrm{No}$ & & & & & & & & \\
\hline Low education partner & & & & 3.16 & & & & 1.45 \\
\hline & & & & $(0.25)$ & & & & $(0.44)$ \\
\hline Medium education partner & & & & 2.91 & & & & 1.22 \\
\hline & & & & $(0.10)$ & & & & $(0.34)$ \\
\hline Higher education partner & & & & 2.72 & & & & 1.26 \\
\hline & & & & $(0.16)$ & & & & $(0.37)$ \\
\hline NA education partner & & & & 0.56 & & & & 0.04 \\
\hline & & & & $(0.20)$ & & & & $(0.44)$ \\
\hline Poland & M1 & M2 & M3 & M4 & M1 & M2 & M3 & M4 \\
\hline Earnings potential & -0.03 & 0.02 & -0.15 & -0.13 & -0.12 & -0.08 & -0.09 & -0.03 \\
\hline & $(0.07)$ & $(0.07)$ & $(0.07)$ & $(0.07)$ & $(0.07)$ & $(0.08)$ & $(0.07)$ & $(0.08)$ \\
\hline Share of women & & -0.01 & 0.00 & 0.00 & & 0.00 & 0.00 & 0.00 \\
\hline & & $(0.00)$ & $(0.00)$ & $(0.00)$ & & $(0.00)$ & $(0.00)$ & $(0.00)$ \\
\hline In union (Ref=Not in union) & & & 2.82 & & & & 1.17 & \\
\hline & & & $(0.07)$ & & & & $(0.20)$ & \\
\hline Partner's education $(\mathrm{Ref}=\mathrm{No}$ & & & & & & & & \\
\hline Low education partner & & & & 3.10 & & & & 1.61 \\
\hline & & & & $(0.22)$ & & & & $(0.27)$ \\
\hline Medium education partner & & & & 2.82 & & & & 1.17 \\
\hline & & & & $(0.07)$ & & & & $(0.20)$ \\
\hline Higher education partner & & & & 2.75 & & & & 0.95 \\
\hline & & & & $(0.09)$ & & & & $(0.22)$ \\
\hline NA education partner & & & & 2.26 & & & & 1.00 \\
\hline & & & & $(1.04)$ & & & & (0.68) \\
\hline Romania & M1 & M2 & M3 & M4 & M1 & M2 & M3 & M4 \\
\hline Earnings potential & -0.07 & -0.12 & -0.08 & 0.03 & -0.49 & -0.50 & -0.40 & -0.23 \\
\hline & $(0.10)$ & $(0.11)$ & $(0.09)$ & $(0.10)$ & $(0.12)$ & $(0.13)$ & $(0.12)$ & $(0.14)$ \\
\hline Share of women & & 0.01 & 0.00 & 0.00 & & 0.00 & 0.00 & 0.00 \\
\hline & & $(0.00)$ & $(0.00)$ & $(0.00)$ & & $(0.00)$ & $(0.00)$ & $(0.00)$ \\
\hline In union (Ref=Not in union) & & & 3.72 & & & & 1.71 & \\
\hline & & & $(0.10)$ & & & & $(0.44)$ & \\
\hline Partner's education (Ref=No & & & & & & & & \\
\hline Low education partner & & & & 4.01 & & & & 2.21 \\
\hline & & & & $(0.13)$ & & & & $(0.45)$ \\
\hline Medium education partner & & & & 3.83 & & & & 1.79 \\
\hline & & & & $(0.11)$ & & & & $(0.45)$ \\
\hline Higher education partner & & & & 3.34 & & & & 1.19 \\
\hline & & & & $(0.19)$ & & & & $(0.54)$ \\
\hline NA education partner & & & & 2.35 & & & & 0.82 \\
\hline & & & & $(0.22)$ & & & & $(0.50)$ \\
\hline
\end{tabular}

Notes: Robust standard errors in parentheses; estimates with p-values $<0.05$ in bold. All models include: duration splines, age at graduation/first birth, cohorts, father's and mother's education, number of siblings. 
Table 4 shows the results for women. Overall, we found no evidence for H1b, according to which higher earnings potential is negatively associated with women's fertility rates due to opportunity costs. In general, with regard to the transition to motherhood we find no statistically significant effect of earnings potential. Next, we find that earnings potential is positively associated with women's second-birth rates in Austria and Belgium, whereas in other countries there is no statistically significant effect. The inclusion of partnership status to some extent inhibits the size of the effect in Austria and Belgium. Nonsignificant effects turn out to be strongly negative and statistically significant in Lithuania and Poland. It should be mentioned that, for all countries, if we did not account for unobserved heterogeneity in our models, the positive effect of women's earnings potential on the transition to second birth would have been inflated (results available upon request). In Romania, where we could not run the model with unobserved heterogeneity, we found a nonsignificant and small effect of women's earnings potential for second births. Plausibly, as it also holds for others Central and Eastern European countries, this would have turned into a stronger negative effect if we had been able to include a random effect capturing variation across women's birth episodes.

The gender composition of the study discipline has a small effect on women's fertility rates. However, despite the small effect, when the gender composition is statistically significant its effect is consistently positive in most of the countries. This supports our hypothesis ( $\mathrm{H} 2 \mathrm{~b})$, according to which a higher share of women in a woman's chosen study discipline may reinforce gender-stereotypical behaviors, which in turn may boost their fertility.

Table 4: Model estimates for the transition to first and second births, female sample

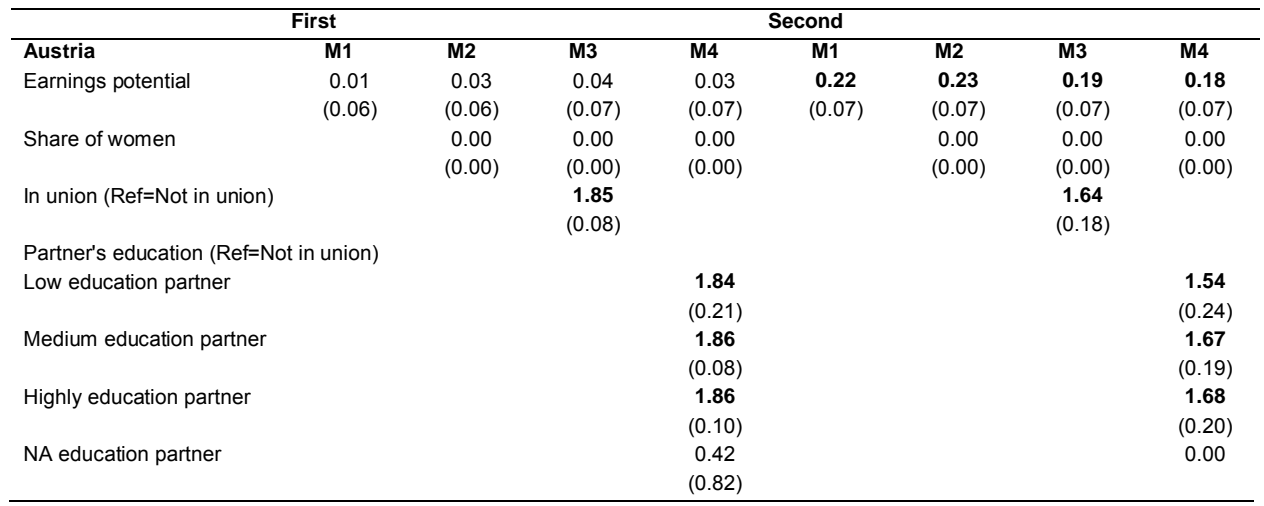


Table 4: $\quad$ (Continued)

\begin{tabular}{|c|c|c|c|c|c|c|c|c|}
\hline \multirow{2}{*}{ Belgium } & \multicolumn{4}{|c|}{ First } & \multicolumn{4}{|l|}{ Second } \\
\hline & M1 & M2 & M3 & M4 & M1 & M2 & M3 & M4 \\
\hline \multirow[t]{2}{*}{ Earnings potential } & -0.08 & -0.08 & -0.13 & -0.19 & 0.12 & 0.13 & 0.13 & 0.05 \\
\hline & $(0.06)$ & $(0.06)$ & $(0.06)$ & $(0.05)$ & $(0.06)$ & $(0.06)$ & $(0.06)$ & $(0.06)$ \\
\hline \multirow[t]{2}{*}{ Share of women } & & 0.00 & 0.00 & 0.00 & & 0.00 & 0.00 & 0.00 \\
\hline & & $(0.00)$ & $(0.00)$ & $(0.00)$ & & $(0.00)$ & $(0.00)$ & $(0.00)$ \\
\hline \multirow[t]{2}{*}{ In union (Ref=Not in union) } & & & 2.22 & & & & 0.96 & \\
\hline & & & $(0.12)$ & & & & $(0.21)$ & \\
\hline \multicolumn{9}{|c|}{ Partner's education (Ref=Not in union) } \\
\hline \multirow[t]{2}{*}{ Low education partner } & & & & 2.45 & & & & 0.94 \\
\hline & & & & $(0.18)$ & & & & $(0.23)$ \\
\hline \multirow[t]{2}{*}{ Medium education partner } & & & & 2.44 & & & & 1.11 \\
\hline & & & & $(0.13)$ & & & & $(0.22)$ \\
\hline \multirow[t]{2}{*}{ Highly education partner } & & & & 2.57 & & & & 1.46 \\
\hline & & & & $(0.13)$ & & & & $(0.23)$ \\
\hline \multirow[t]{2}{*}{ NA education partner } & & & & 1.55 & & & & 0.27 \\
\hline & & & & $(0.13)$ & & & & $(0.23)$ \\
\hline Bulgaria & M1 & M2 & M3 & M4 & M1 & M2 & M3 & M4 \\
\hline \multirow[t]{2}{*}{ Earnings potential } & -0.01 & 0.02 & -0.03 & -0.04 & -0.06 & -0.06 & -0.09 & -0.12 \\
\hline & $(0.06)$ & $(0.06)$ & $(0.06)$ & $(0.07)$ & $(0.07)$ & $(0.07)$ & $(0.06)$ & $(0.07)$ \\
\hline \multirow[t]{2}{*}{ Share of women } & & 0.00 & 0.00 & 0.00 & & 0.00 & 0.00 & 0.00 \\
\hline & & $(0.00)$ & $(0.00)$ & $(0.00)$ & & $(0.00)$ & $(0.00)$ & $(0.00)$ \\
\hline \multirow[t]{2}{*}{ In union (Ref=Not in union) } & & & 2.81 & & & & 1.82 & \\
\hline & & & $(0.07)$ & & & & $(0.23)$ & \\
\hline \multicolumn{9}{|c|}{ Partner's education (Ref=Not in union) } \\
\hline \multirow[t]{2}{*}{ Low education partner } & & & & 2.59 & & & & 1.78 \\
\hline & & & & $(0.14)$ & & & & $(0.27)$ \\
\hline \multirow[t]{2}{*}{ Medium education partner } & & & & 2.81 & & & & 1.79 \\
\hline & & & & $(0.07)$ & & & & $(0.23)$ \\
\hline \multirow[t]{2}{*}{ Highly education partner } & & & & 2.96 & & & & 2.01 \\
\hline & & & & $(0.12)$ & & & & $(0.26)$ \\
\hline \multirow[t]{2}{*}{ NA education partner } & & & & 1.96 & & & & 1.83 \\
\hline & & & & $(0.42)$ & & & & $(0.73)$ \\
\hline Lithuania & M1 & M2 & M3 & M4 & M1 & M2 & M3 & M4 \\
\hline \multirow[t]{2}{*}{ Earnings potential } & -0.04 & -0.01 & -0.05 & -0.04 & -0.02 & -0.04 & -0.18 & -0.19 \\
\hline & $(0.04)$ & $(0.05)$ & $(0.06)$ & $(0.06)$ & $(0.07)$ & $(0.07)$ & $(0.07)$ & $(0.07)$ \\
\hline Share of women & & 0.00 & 0.00 & 0.00 & & 0.00 & 0.00 & 0.00 \\
\hline & & $(0.00)$ & $(0.00)$ & $(0.00)$ & & $(0.00)$ & $(0.00)$ & $(0.00)$ \\
\hline In union (Ref=Not in union) & & & 2.26 & & & & 1.48 & \\
\hline & & & $(0.09)$ & & & & $(0.19)$ & \\
\hline Partner's education $(\mathrm{Ref}=\mathrm{No}$ & t in union) & & & & & & & \\
\hline Low education partner & & & & 2.58 & & & & 1.75 \\
\hline & & & & $(0.22)$ & & & & $(0.29)$ \\
\hline Medium education partner & & & & 2.45 & & & & 1.66 \\
\hline & & & & $(0.10)$ & & & & $(0.20)$ \\
\hline Highly education partner & & & & 2.31 & & & & 1.72 \\
\hline & & & & $(0.14)$ & & & & $(0.23)$ \\
\hline NA education partner & & & & 1.81 & & & & 1.00 \\
\hline & & & & $(0.14)$ & & & & $(0.22)$ \\
\hline
\end{tabular}


Trimarchi \& Van Bavel: Gender differences and similarities in the educational gradient in fertility

Table 4: (Continued)

\begin{tabular}{|c|c|c|c|c|c|c|c|c|}
\hline & First & & & & Second & & & \\
\hline Poland & M1 & M2 & M3 & M4 & M1 & M2 & M3 & M4 \\
\hline \multirow[t]{2}{*}{ Earnings potential } & -0.07 & -0.07 & -0.15 & -0.14 & -0.10 & -0.07 & -0.14 & -0.14 \\
\hline & $(0.03)$ & $(0.04)$ & $(0.04)$ & $(0.04)$ & $(0.04)$ & $(0.04)$ & $(0.04)$ & $(0.05)$ \\
\hline \multirow[t]{2}{*}{ Share of women } & & 0.00 & 0.00 & 0.00 & & 0.00 & 0.00 & 0.00 \\
\hline & & $(0.00)$ & $(0.00)$ & $(0.00)$ & & $(0.00)$ & $(0.00)$ & $(0.00)$ \\
\hline \multirow[t]{2}{*}{ In union (Ref=Not in union) } & & & 2.27 & & & & 1.41 & \\
\hline & & & $(0.06)$ & & & & $(0.14)$ & \\
\hline \multicolumn{9}{|c|}{ Partner's education (Ref=Not in union) } \\
\hline \multirow[t]{2}{*}{ Low education partner } & & & & 1.78 & & & & 1.33 \\
\hline & & & & $(0.17)$ & & & & $(0.18)$ \\
\hline \multirow[t]{2}{*}{ Medium education partner } & & & & 2.31 & & & & 1.42 \\
\hline & & & & $(0.06)$ & & & & $(0.14)$ \\
\hline \multirow[t]{2}{*}{ Highly education partner } & & & & 2.27 & & & & 1.40 \\
\hline & & & & $(0.09)$ & & & & $(0.17)$ \\
\hline \multirow[t]{2}{*}{ NA education partner } & & & & 1.85 & & & & 2.19 \\
\hline & & & & $(0.69)$ & & & & $(0.41)$ \\
\hline Romania & M1 & M2 & M3 & M4 & M1 & M2 & M3 & M4 \\
\hline Earnings potential & $\begin{array}{c}-0.05 \\
(0.05)\end{array}$ & $\begin{array}{c}-0.09 \\
(0.05)\end{array}$ & $\begin{array}{c}-0.14 \\
(0.06)\end{array}$ & $\begin{array}{c}-0.13 \\
(0.06)\end{array}$ & $\begin{array}{c}-0.10 \\
(0.07)\end{array}$ & $\begin{array}{c}0.00 \\
(0.09)\end{array}$ & $\begin{array}{c}0.01 \\
(0.09)\end{array}$ & $\begin{array}{c}0.00 \\
(0.09)\end{array}$ \\
\hline Share of women & & $\begin{array}{c}0.00 \\
(0.00)\end{array}$ & $\begin{array}{c}0.01 \\
(0.00)\end{array}$ & $\begin{array}{c}\mathbf{0 . 0 1} \\
(0.00)\end{array}$ & & $\begin{array}{c}-0.01 \\
(0.01)\end{array}$ & $\begin{array}{c}-0.01 \\
(0.00)\end{array}$ & $\begin{array}{r}-0.01 \\
(0.01)\end{array}$ \\
\hline In union (Ref=Not in union) & & & $\begin{array}{c}2.88 \\
(0.10)\end{array}$ & & & & $\begin{array}{c}0.75 \\
(0.28)\end{array}$ & \\
\hline \multicolumn{9}{|c|}{ Partner's education (Ref=Not in union) } \\
\hline \multirow[t]{2}{*}{ Low education partner } & & & & 2.88 & & & & 1.03 \\
\hline & & & & $(0.20)$ & & & & $(0.33)$ \\
\hline \multirow{2}{*}{\multicolumn{2}{|c|}{ Medium education partner }} & & & 2.94 & & & & 0.78 \\
\hline & & & & $(0.11)$ & & & & $(0.28)$ \\
\hline \multirow[t]{2}{*}{ Highly education partner } & & & & 2.84 & & & & 0.83 \\
\hline & & & & $(0.18)$ & & & & $(0.34)$ \\
\hline \multirow[t]{2}{*}{ NA education partner } & & & & 2.62 & & & & 0.26 \\
\hline & & & & $(0.15)$ & & & & $(0.34)$ \\
\hline
\end{tabular}

Notes: Robust standard errors in parentheses; estimates with p-values < 0.05 in bold. All models include: duration splines, age at graduation/first birth, cohorts, father's and mother's education, number of siblings.

\section{Discussion}

This study provides insights into the role of the field of study in predicting men's and women's fertility. First, we explored the predictive power of the study discipline for both men's and women's fertility rates. We found that in countries where the field of study is relatively important for men's fertility, this is less the case for women's fertility. Next, we focused on the role of earnings potential and the gender composition of the study discipline in understanding the link between field of study and fertility. In general, we found heterogeneity across countries and more similarities between genders within countries. Our first hypothesis expects a positive effect of earnings potential for men's fertility rates, driven by an income effect (H1a), and a negative effect for 
women's fertility rates, driven by opportunity costs (H1b). In line with H1a, we found a positive effect of earnings potential on men's second-birth rates in Belgium. In Central and Eastern European countries, if the effect of earnings potential was significant it was negatively associated with men's birth rates. In these countries the negative effect of men's earnings potential tends to be no longer statistically significant after accounting for partners' educational level. These results may be due to selection-into-union and educational assortative mating: men with higher earnings potential are more likely to enter into a union, perhaps because they are more attractive in the mating market, boosting their fertility (Trimarchi and Van Bavel 2017). In addition, highly educated men and women, who have higher earnings potential, tend to form homogamous unions. If we do not include partners' educational level in the model, men's estimates may embed the negative effect of women's education. Vice versa, women's estimates may embed the positive effect of men's education.

For women, if the effect of earnings potential was statistically significant, it tended to be negative for both first and second-birth rates. Due to the role of assortative mating, this negative association was stronger once we accounted for partnership status and partners' educational level. Austria and Belgium are exceptions because women's earnings potential is positively associated with second-birth rates. While this is to some extent expected in Belgium, given its family-friendly policies (Wood, Neels, and Kil 2014), the finding for Austria is more puzzling. After further inspection we found that this is driven by women who graduated in Health and Welfare, a female-dominated field that leads to family-friendly occupations, mostly in the public sector (Neyer, Hoem, and Andersson 2017). We did not find support for our second hypothesis, according to which study disciplines with a higher share of one's own sex enhance fertility.

An important limitation of the present paper is that, by estimating earnings potential with cross-sectional data relating to the 2009-2013 period, we assumed that the relative difference in earnings potential between study disciplines remained largely unchanged over time. Unfortunately, we are not able to test this assumption, given that the EU-LFS only has both income and field of study information from 2009 onwards. Additionally, given the limitations of the data, we had to proceed with rather broad categories of fields of study. For instance, we had to group individuals who graduated in business and management in the same category as those who followed cultural studies, even though these groups tend to have diverging earnings potentials. However, previous studies have rarely been able to estimate the earnings potential of study disciplines at all. Following Van Bavel (2010), we have been able to do so while at the same time accounting for differences by country and gender.

Overall, our results point towards large heterogeneity across countries. The role that the field of study and its characteristics play in men and women's fertility is 
inherently attached to contextual factors. Due to the small number of countries that we could include in our study, we could not empirically test how contextual factors shape gender differences in fertility rates. Additionally, our sample of countries cannot be considered representative of all European regions. Due to data limitation, we included four countries from Central Eastern Europe (Bulgaria, Lithuania, Poland, and Romania) and two from Western Europe (Austria and Belgium). These two groups of countries differ in several cultural and socioeconomic factors rooted in their historical background. In particular, the results highlight differences between these countries regarding the role of men and women in the family. To some extent, our findings reflect the fact that these countries are at different stages in the 'Gender Revolution.' In the Western group we found that women's earnings potential has a positive effect on the transition to second births. This group is often considered to be at a more advanced stage of the Gender Revolution than the Central Eastern group (Goldscheider et al. 2015). Plausibly, Northern European countries would have also shown a positive effect of both men's and women's earnings potential on fertility rates, whereas Southern European countries would have been closer to the findings for the Central and Eastern European group. To study the role of contextual factors in shaping differences (or similarities) in men's and women's fertility determinants remains a challenge for future studies.

In this paper we have (re)considered the role of men in fertility. While scholars have kept track of women's family behavior and how things have changed for women because of their increasing involvement in higher education and their ensuing labor force participation, much less is known about men's family behavior. To some extent, as also suggested by this study, the drivers of men's and women's family behavior may be more similar than is often assumed. Scholars have suggested that the societal changes of the last decades, such as increasing involvement of men in household and childrearing activities, may lead to a more active role for men in fertility decisionmaking. (Goldscheider, Oláh, and Puur 2010; Van Bavel 2012; Huinink and Kohli 2014). This stronger role may remain unnoticed if we continue to focus only on women.

\section{Acknowledgements}

Part of this research has been carried out while the first author was employed at the Centre for Sociological Research of the University of Leuven in Belgium. The research leading to these results has received funding from the European Research Council under the European Union's Seventh Framework Program (FP/2007-2013)/ERC Grant Agreement no. 312290 for the GENDERBALL project (2013-2017). 


\section{References}

Bartus, T., Murinkó, L., Szalma, I., and Szél, B. (2013). The effect of education on second births in Hungary. Demographic Research 28(1): 1-32. doi:10.4054/ DemRes.2013.28.1.

Becker, G.S. (1991). A treatise on the family. Cambridge: Harvard University Press.

Begall, K. and Mills, M.C. (2013). The influence of educational field, occupation, and occupational sex segregation on fertility in the Netherlands. European Sociological Review 29(4): 720-742. doi:10.1093/esr/jcs051.

Blau, F.D. and Kahn, L.M. (2016). The gender wage gap: Extent, trends, and explanations. Bonn: Forschungsinstitut zur Zukunft der Arbeit (IZA discussion paper series 9656).

Blossfeld, H.-P., Klijzing, E., Mills, M., and Kurz, K. (2005). Globalisation, uncertainty, and youth in society. London: Routledge.

Cech, E. (2015). Mechanism or myth? Family plans and the reproduction of occupational gender segregation. Gender and Society 30(2): 265-288. doi: $10.1177 / 0891243215608798$.

Charles, M. and Bradley, K. (2009). Indulging our gendered selves? Sex segregation by field of study in 44 countries. American Journal of Sociology 114(4): 924-976. doi:10.1086/595942.

Charles, M. (2011). What gender is science? Contexts 10(2): 22-28. doi:10.1177/ 1536504211408795 .

Cigno, A. (1991). Economics of the family. Oxford: Clarendon Press.

Cigno, A. and Ermisch, J. (1989). A microeconomic analysis of the timing of births. European Economic Review 33(4): 737-760. doi:10.1016/0014-2921(89)900 23-8.

Cooney, T.M. and Uhlenberg, P. (1989). Family-building patterns of professional women: A comparison of lawyers, physicians, and postsecondary teachers. Journal of Marriage and Family 51(3): 749-758. doi:10.2307/352173.

Corijn, M. and Klijzing, E. (2001). Transition to adulthood in Europe. Dordrecht: Klawuer Publishers. doi:10.1007/978-94-015-9717-3. 
Esping-Andersen, G. and Billari, F.C. (2015). Re-theorizing family demographics. Population and Development Review 41(1): 1-31. doi:10.1111/j.1728-4457. 2015.00024.x.

Esteve, A., García-Román, J., and Permanyer, I. (2012). The gender-gap reversal in education and its effect on union formation: The end of hypergamy? Population and Development Review 38(3): 535-546. doi:10.1111/j.1728-4457.2012. 00515.x.

Gerster, M., Keiding, N., Knudsen, L.B., and Strandberg-Larsen, K. (2007). Education and second birth rates in Denmark 1981-1994. Demographic Research 17(8): 181-210. doi:10.4054/DemRes.2007.17.8.

Goldscheider, F., Bernhardt, E., and Lappegård, T. (2015). The gender revolution: A framework for understanding changing family and demographic behavior. Population and Development Review 41(2): 207-239. doi:10.1111/j.1728-4457. 2015.00045.x.

Goldscheider, F., Oláh, L.S., and Puur, A. (2010). Reconciling studies of men's gender attitudes and fertility. Demographic Research 22(8): 189-198. doi:10.4054/Dem Res.2010.22.8.

Gustafsson, S. (2001). Optimal age at motherhood: Theoretical and empirical. Journal of Population Economics 14(2): 225-247. doi:10.1007/s001480000051.

Hakim, C. (2003). A new approach to explaining fertility patterns: Preference theory. Population and Development Review 29(3): 349-374. doi:10.1111/j.1728-4457. 2003.00349.x.

Hoem, J.M., Neyer, G., and Andersson, G. (2006a). Education and childlessness. Demographic Research 14(15): 331-380. doi:10.4054/DemRes.2006.14.15.

Hoem, J.M., Neyer, G., and Andersson, G. (2006b). Educational attainment and ultimate fertility among Swedish women born in 1955-59. Demographic Research 14(16): 381-404. doi:10.4054/DemRes.2006.14.16.

Huinink, J. and Kohli, M. (2014). A life-course approach to fertility. Demographic Research 30(45): 1293-1326. doi:10.4054/DemRes.2014.30.45.

ISCED (1997). International standard classification of education http://www.une sco.org/education/information/nfsunesco/doc/isced_1997.htm. 
Klesment, M., Puur, A., Rahnu, L., and Sakkeus, L. (2014). Varying association between education and second births in Europe: Comparative analysis based on the EU-SILC data. Demographic Research 31(27): 813-860. doi:10.4054/Dem Res.2014.31.27.

Kravdal, Ø. (2001). The high fertility of college educated women in Norway. Demographic Research 5(6): 187-216. doi:10.4054/DemRes.2001.5.6.

Kravdal, Ø. (2007). Effects of current education on second- and third-birth rates among Norwegian women and men born in 1964: Substantive interpretations and methodological issues. Demographic Research 17(9): 211-246. doi:10.4054/ DemRes.2007.17.9.

Kravdal, Ø. and Rindfuss, R. (2008). Changing relationships between education and fertility: A study of women and men born 1940 to 1964. American Sociological Review 73(5): 854-873. doi:10.1177/000312240807300508.

Kreyenfeld, M. (2002). Time squeeze, partner effect or self-selection? Demographic Research 7(2): 15-48. doi:10.4054/DemRes.2002.7.2.

Kreyenfeld, M. and Konietzka, D. (2008). Education and fertility in Germany. In: Hamm, I., Seitz, H., and Werding, M. (eds.). Demographic change in Germany. Berlin: Springer: $165-187$.

Lappegård, T. and Rønsen, M. (2005). The multifaceted impact of education on entry into motherhood. European Journal of Population 21(1): 31-49. doi:10.1007/ s10680-004-6756-9.

Lappegård, T. and Rønsen, M. (2013). Socioeconomic differences in multipartner fertility among Norwegian men. Demography 50(3): 1135-1153. doi:10.1007/ s13524-012-0165-1.

Lappegård, T., Rønsen, M., and Skrede, K. (2011). Fatherhood and fertility. Fathering 9(1): 103-120. doi:10.3149/fth.0901.103.

Lillard, L. and Panis, C.W. (2003). aML Multilevel Multiprocess Statistical Software, version 2.0 [electronic resource]. Los Angeles: EconWare. http://www.appliedml.com.

Martín-García, T. (2009). ‘Bring men back in’: A re-examination of the impact of type of education and educational enrolment on first births in Spain. European Sociological Review 25(2): 199-213. doi:10.1093/esr/jen041. 
Martín-García, T. and Baizan, P. (2006). The impact of the type of education and of educational enrolment on first births. European Sociological Review 22(3): 259275. doi:10.1093/esr/jci056.

Michelmore, K. and Musick, K. (2013). Fertility patterns of college graduates by field of study, US women born 1960-79. Population Studies 68(3): 37-41. doi: $10.1080 / 00324728.2013 .847971$.

Neyer, G., Hoem, J.M., and Andersson, G. (2017). Education and childlessness: The influence of educational field and educational level on childlessness among Swedish and Austrian women. In: Kreyenfeld, M. and Konietzka, D. (eds.). Childlessness in Europe: Contexts, causes, and consequences. Cham: Springer Nature: 183-208. doi:10.1007/978-3-319-44667-7_9.

Nisén, J., Martikainen, P., Myrskylä, M., and Silventoinen, K. (2017). Education, other socioeconomic characteristics across the life course, and fertility among Finnish men. European Journal of Population: 1-30. doi:10.1007/s10680-017-9430-8.

Nisén, J., Martikainen, P., Silventoinen, K., and Myrskylä, M. (2014). Age-specific fertility by educational level in the Finnish male cohort born 1940-1950. Demographic Research 31(5): 119-136. doi:10.4054/DemRes.2014.31.5.

Ohlsson-Wijk, S. (2015a). Family formation in Sweden around the turn of the new millennium [PhD thesis]. Stockholm: University of Stockholm, Department of Sociology.

Ohlsson-Wijk, S. (2015b). Workplace sex composition and the transition to parenthood: Men and women in Sweden. Stockholm: Stockholm University (Stockholm Research Reports in Demography 12).

Okamoto, D. and England, P. (1999). Is there a supply side to occupational sex segregation? Sociological Perspectives 42(4): 557-582. doi:10.2307/1389574.

Oppenheimer, V. (1994). Women's rising employment and the future of the family in industrial societies. Population and Development Review 20(2): 293-342. doi: $10.2307 / 2137521$.

Oppermann, A. (2014). Exploring the relationship between educational field and transition to parenthood: An analysis of women and men in western Germany. European Sociological Review 30(6): 728-749. doi:10.1093/esr/jcu070.

Rindfuss, R., Morgan, P., and Swicegood, G. (1988). First births in America: Changes in the timing of parenthood. Berkeley: University of California Press. 
Tesching, K. (2012). Education and fertility: Dynamic interrelations between women's educational level, educational field and fertility in Sweden [PhD thesis]. Stockholm: University of Stockholm, Department of Sociology.

Tragaki, A. and Bagavos, C. (2014). Male fertility in Greece: Trends and differentials by education level and employment status. Demographic Research 31(6): $137-$ 160. doi:10.4054/DemRes.2014.31.6.

Trimarchi, A. and Van Bavel, J. (2017). Education and the transition to fatherhood: The role of selection into union. Demography 54(1): 119-144. doi:10.1007/s13524016-0533-3.

Van Bavel, J. (2010). Choice of study discipline and the postponement of motherhood in Europe: The impact of expected earnings, gender composition, and family attitudes. Demography 47(2): 439-458. doi:10.1353/dem.0.0108.

Van Bavel, J. (2012). The reversal of gender inequality in education, union formation and fertility in Europe. Vienna Yearbook of Population Research 10(1): 127154. doi:10.2307/41941000.

Vincent-Lancrin, S. (2008). The reversal of gender inequalities in higher education: An on-going trend. Higher education to 2030. Volume 1: 265-298. Retrieved from https://www1.oecd.org/edu/ceri/41939699.pdf.

Winkler-Dworak, M. and Toulemon, L. (2007). Gender differences in the transition to adulthood in France: Is there convergence over the recent period? European Journal of Population 23(3): 273-314. doi:10.1007/s10680-007-9128-4.

Wood, J., Neels, K., and Kil, T. (2014). The educational gradient of childlessness and cohort parity progression in 14 low fertility countries. Demographic Research 31(46): 1365-1416. doi:10.4054/DemRes.2014.31.46.

Xie, Y., Raymo, J.M., Goyette, K., and Thornton, A. (2003). Economic potential and entry into marriage and cohabitation. Demography 40(2): 351-367. doi:10.1353/ dem.2003.0019. 
Trimarchi \& Van Bavel: Gender differences and similarities in the educational gradient in fertility

\section{Appendix}

Figure A-1: Regression-coefficients by country, men

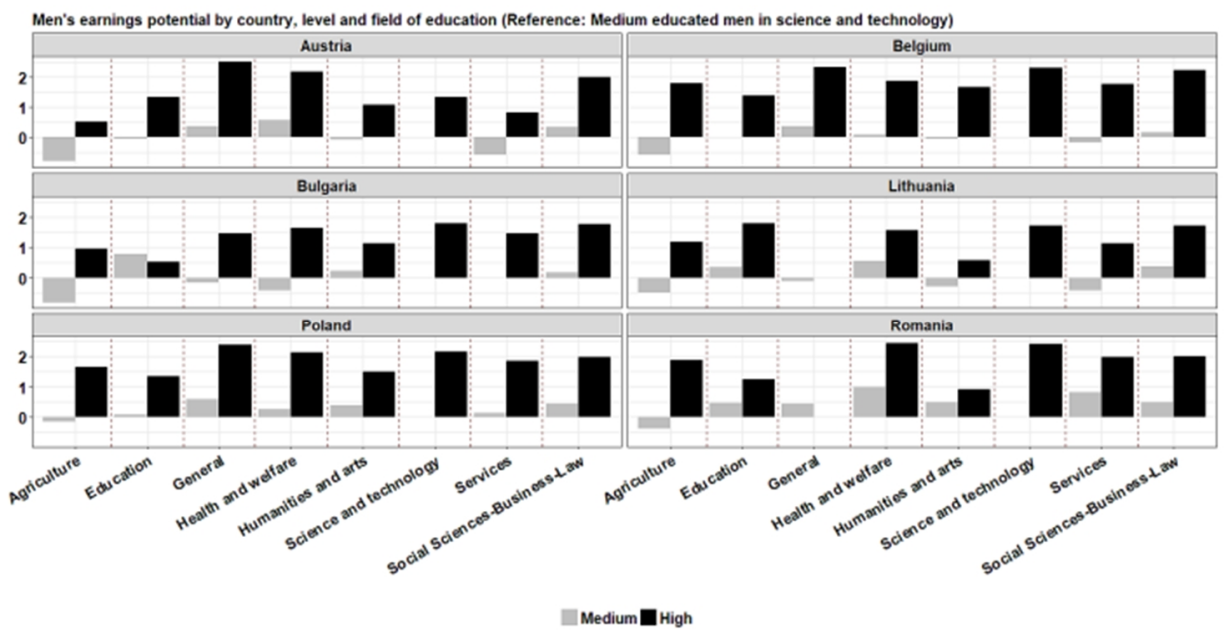

Note: The bars indicate the size of $\beta_{5}$, i.e., men's earnings potential by field of study and level of education.

Figure A-2: Regression-coefficients by country, women

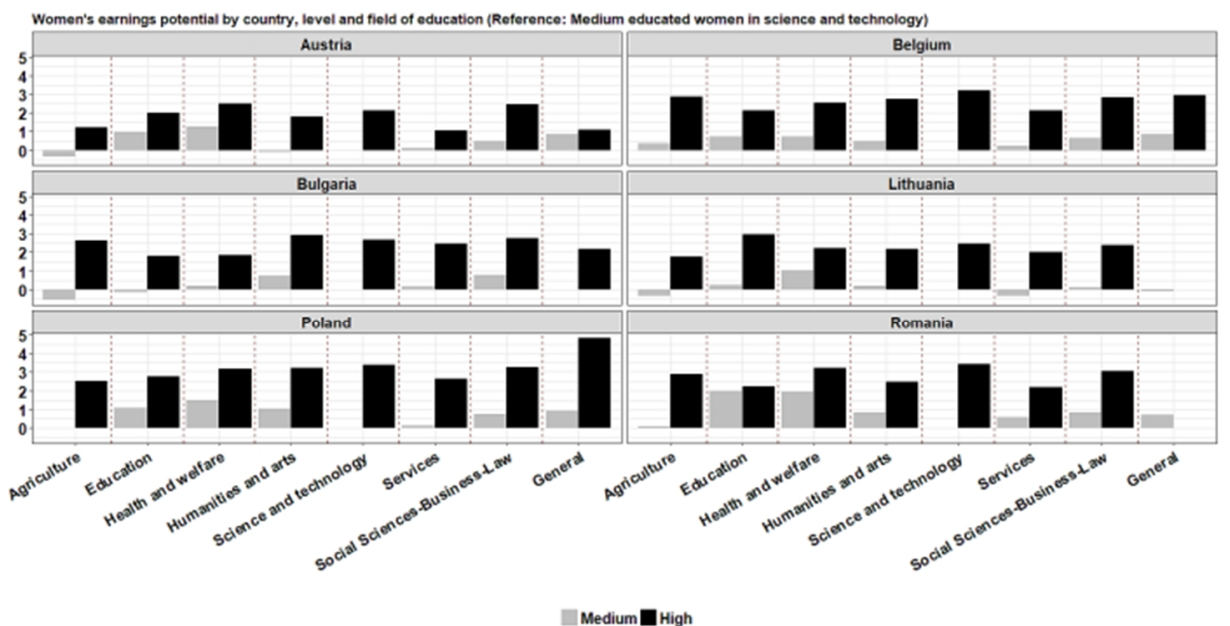

Note: The bars indicate the size of $\boldsymbol{\beta}_{5}$, i.e., women's earnings potential by field of study and level of education. 
Table A-1: Effects of control variables for the transition to first and second births, full model (M4), male sample

\begin{tabular}{|c|c|c|c|c|c|c|}
\hline First birth & Austria & Belgium & Bulgaria & Lithuania & Poland & Romania \\
\hline \multicolumn{7}{|c|}{ Splines: Time since graduation } \\
\hline \multirow[t]{2}{*}{ dur0-2 } & 0.13 & 0.09 & 0.10 & 0.12 & 0.26 ** & 0.02 \\
\hline & $(0.17)$ & $(0.22)$ & $(0.11)$ & $(0.10)$ & $(0.08)$ & $(0.14)$ \\
\hline \multirow[t]{2}{*}{ dur2-4 } & 0.15 & $0.52^{* * *}$ & $0.29^{* * *}$ & 0.12 & $0.23^{* * *}$ & 0.18 * \\
\hline & $(0.11)$ & $(0.13)$ & $(0.08)$ & $(0.08)$ & $(0.06)$ & $(0.09)$ \\
\hline \multirow[t]{2}{*}{ dur4-6 } & 0.20 * & 0.03 & 0.03 & -0.05 & -0.04 & 0.14 * \\
\hline & $(0.09)$ & $(0.09)$ & $(0.06)$ & $(0.07)$ & $(0.05)$ & $(0.07)$ \\
\hline \multirow[t]{2}{*}{ dur6-10 } & -0.06 & -0.01 & $-0.12^{* *}$ & -0.06 & -0.01 & $-0.11^{* *}$ \\
\hline & $(0.04)$ & $(0.04)$ & $(0.04)$ & $(0.04)$ & $(0.03)$ & $(0.03)$ \\
\hline \multirow[t]{2}{*}{ dur10-15 } & 0.00 & -0.06 & $-0.13^{*}$ & $-0.23^{* \star *}$ & $-0.12^{\star \star *}$ & $-0.14^{* * *}$ \\
\hline & $(0.04)$ & $(0.04)$ & $(0.05)$ & $(0.06)$ & $(0.03)$ & $(0.04)$ \\
\hline \multirow[t]{2}{*}{ dur15+ } & -0.14 * & $-0.21^{* * *}$ & -0.10 & -0.14 & $-0.15^{\star \star *}$ & $-0.28^{* * *}$ \\
\hline & $(0.06)$ & $(0.06)$ & $(0.07)$ & $(0.08)$ & $(0.04)$ & $(0.06)$ \\
\hline \multirow[t]{2}{*}{ Constant } & $-5.39^{* * *}$ & $-8.42^{\star \star \star}$ & $-9.28^{* * *}$ & -4.90 * & $-6.21^{* \star *}$ & $-9.28^{* * *}$ \\
\hline & $(1.43)$ & $(1.96)$ & $(2.11)$ & $(1.95)$ & $(1.16)$ & $(1.71)$ \\
\hline \multicolumn{7}{|c|}{ Cohort (Ref=1970-1979) } \\
\hline \multirow[t]{2}{*}{$1960-1969$} & $0.33^{* \star *}$ & 0.23 * & 0.51 *** & $0.44 * * *$ & $0.28^{* * *}$ & $0.36^{* * *}$ \\
\hline & $(0.10)$ & $(0.10)$ & $(0.10)$ & $(0.09)$ & $(0.07)$ & $(0.09)$ \\
\hline \multirow[t]{2}{*}{ 1980-1987 } & -0.41 * & -0.54 ** & $-0.78^{* *}$ & $-0.79^{* * *}$ & $-0.46^{* \star *}$ & -0.81 ** \\
\hline & $(0.17)$ & $(0.20)$ & $(0.25)$ & $(0.19)$ & $(0.09)$ & $(0.30)$ \\
\hline \multirow[t]{2}{*}{ Age at graduation } & 0.04 & 0.21 & 0.36 & 0.11 & 0.20 * & 0.42 ** \\
\hline & $(0.12)$ & $(0.17)$ & $(0.19)$ & $(0.17)$ & $(0.10)$ & $(0.16)$ \\
\hline \multirow[t]{2}{*}{ Age at graduation2 } & 0.00 & 0.00 & -0.01 & 0.00 & -0.01 * & -0.01 ** \\
\hline & $(0.00)$ & $(0.00)$ & $(0.00)$ & $(0.00)$ & $(0.00)$ & $(0.00)$ \\
\hline \multicolumn{7}{|c|}{ Father's education (Ref=Low) } \\
\hline \multirow[t]{2}{*}{ Medium } & -0.15 & 0.03 & -0.16 & -0.04 & 0.08 & -0.13 \\
\hline & $(0.11)$ & $(0.13)$ & $(0.12)$ & $(0.12)$ & $(0.10)$ & $(0.10)$ \\
\hline \multirow[t]{2}{*}{ High } & -0.40 & 0.03 & -0.49 * & -0.15 & -0.14 & -0.16 \\
\hline & $(0.25)$ & $(0.15)$ & $(0.21)$ & $(0.21)$ & $(0.16)$ & $(0.33)$ \\
\hline \multirow[t]{2}{*}{ Missing } & -0.08 & 0.03 & 0.02 & -0.13 & -0.04 & -0.14 \\
\hline & $(0.21)$ & $(0.17)$ & $(0.17)$ & $(0.14)$ & $(0.14)$ & $(0.18)$ \\
\hline \multicolumn{7}{|c|}{ Mother's education (Ref=Low) } \\
\hline \multirow[t]{2}{*}{ Medium } & -0.14 & -0.13 & -0.14 & 0.10 & -0.22 * & -0.13 \\
\hline & $(0.11)$ & $(0.13)$ & $(0.12)$ & $(0.12)$ & $(0.09)$ & $(0.12)$ \\
\hline \multirow[t]{2}{*}{ High } & 0.02 & -0.11 & 0.12 & 0.11 & -0.35 * & -0.38 \\
\hline & $(0.31)$ & $(0.15)$ & $(0.19)$ & $(0.20)$ & $(0.16)$ & $(0.36)$ \\
\hline \multirow[t]{2}{*}{ Missing } & -0.03 & -0.17 & -0.22 & 0.14 & 0.01 & -0.10 \\
\hline & $(0.27)$ & $(0.20)$ & $(0.24)$ & $(0.18)$ & $(0.18)$ & $(0.31)$ \\
\hline \multicolumn{7}{|c|}{ N. siblings (Ref=None) } \\
\hline \multirow[t]{2}{*}{1 sibling } & 0.28 & -0.04 & 0.03 & 0.32 * & 0.09 & -0.17 \\
\hline & $(0.17)$ & $(0.16)$ & (0.13) & $(0.14)$ & $(0.12)$ & $(0.14)$ \\
\hline 2 siblings & 0.26 & 0.12 & 0.34 * & $0.47^{\text {** }}$ & 0.18 & 0.05 \\
\hline & $(0.17)$ & $(0.17)$ & $(0.16)$ & $(0.15)$ & $(0.13)$ & $(0.14)$ \\
\hline $3+$ siblings & 0.37 * & 0.16 & 0.21 & 0.49 ** & 0.26 * & 0.07 \\
\hline & $(0.17)$ & $(0.16)$ & $(0.18)$ & $(0.16)$ & $(0.12)$ & $(0.14)$ \\
\hline
\end{tabular}


Trimarchi \& Van Bavel: Gender differences and similarities in the educational gradient in fertility

Table A-1: (Continued)

\begin{tabular}{|c|c|c|c|c|c|c|}
\hline Second birth & Austria & Belgium & Bulgaria & Lithuania & Poland & Romania \\
\hline \multicolumn{7}{|c|}{ Splines: Time since last birth } \\
\hline \multirow[t]{2}{*}{ dur0-2 } & $0.72^{* \star *}$ & $1.03^{* * *}$ & $0.56^{* * *}$ & $0.61^{* * *}$ & $0.42 * * *$ & $0.22 *$ \\
\hline & $(0.10)$ & $(0.09)$ & $(0.09)$ & $(0.10)$ & $(0.06)$ & $(0.09)$ \\
\hline \multirow[t]{2}{*}{ dur2-4 } & -0.14 & $-0.47^{* \star *}$ & -0.09 & $-0.25^{* *}$ & -0.03 & -0.03 \\
\hline & $(0.10)$ & $(0.11)$ & $(0.08)$ & $(0.09)$ & $(0.06)$ & $(0.09)$ \\
\hline \multirow[t]{2}{*}{ dur4-6 } & -0.26 * & $-0.48^{* *}$ & -0.04 & -0.07 & -0.04 & -0.05 \\
\hline & $(0.12)$ & $(0.17)$ & $(0.10)$ & $(0.11)$ & $(0.07)$ & $(0.10)$ \\
\hline \multirow[t]{2}{*}{ dur6-11 } & $-0.17^{*}$ & -0.03 & $-0.42^{* * *}$ & $-0.24^{* * *}$ & $-0.15^{* * *}$ & $-0.25^{\text {*** }}$ \\
\hline & $(0.08)$ & $(0.09)$ & $(0.08)$ & $(0.07)$ & $(0.04)$ & $(0.06)$ \\
\hline \multirow[t]{2}{*}{ dur11+ } & 0.13 & 0.14 & 0.31 & 0.03 & -0.40 * & -0.26 \\
\hline & $(0.19)$ & $(0.17)$ & (0.19) & $(0.15)$ & $(0.16)$ & $(0.21)$ \\
\hline \multirow[t]{2}{*}{ Constant } & -5.92 ** & -1.69 & -8.50 *** & -3.16 & $-5.52^{* \star *}$ & -2.13 \\
\hline & (1.95) & $(2.40)$ & $(2.55)$ & $(2.04)$ & $(1.39)$ & $(2.44)$ \\
\hline \multicolumn{7}{|c|}{ Cohort (Ref=1970-1979) } \\
\hline \multirow[t]{2}{*}{ 1960-1969 } & -0.26 * & 0.27 * & $0.68^{* * *}$ & $0.41^{\star *}$ & 0.24 ** & $0.42^{* \star *}$ \\
\hline & $(0.12)$ & $(0.12)$ & $(0.13)$ & $(0.13)$ & $(0.08)$ & $(0.12)$ \\
\hline \multirow[t]{2}{*}{$1980-1987$} & -0.37 & -0.13 & 0.15 & -1.36 * & -0.38 ** & -1.93 \\
\hline & $(0.32)$ & $(0.32)$ & $(0.60)$ & $(0.59)$ & $(0.14)$ & $(1.18)$ \\
\hline \multirow[t]{2}{*}{ Age at first birth } & 0.07 & -0.21 & 0.30 & -0.10 & 0.11 & -0.18 \\
\hline & $(0.13)$ & $(0.15)$ & $(0.19)$ & $(0.14)$ & $(0.10)$ & $(0.18)$ \\
\hline \multirow[t]{2}{*}{ Age at first birth2 } & 0.00 & 0.00 & -0.01 & 0.00 & 0.00 & 0.00 \\
\hline & $(0.00)$ & $(0.00)$ & $(0.00)$ & $(0.00)$ & $(0.00)$ & $(0.00)$ \\
\hline \multicolumn{7}{|c|}{ Father's education (Ref=Low) } \\
\hline \multirow[t]{2}{*}{ Medium } & -0.24 & 0.11 & -0.10 & -0.27 & -0.04 & 0.07 \\
\hline & $(0.13)$ & $(0.16)$ & $(0.16)$ & $(0.15)$ & $(0.12)$ & $(0.14)$ \\
\hline \multirow[t]{2}{*}{ High } & -0.14 & -0.08 & -0.19 & -0.48 & -0.07 & -0.21 \\
\hline & $(0.36)$ & $(0.17)$ & $(0.31)$ & $(0.27)$ & $(0.20)$ & $(0.55)$ \\
\hline \multirow[t]{2}{*}{ Missing } & -0.49 & -0.31 & -0.23 & -0.30 & -0.15 & -0.48 \\
\hline & $(0.26)$ & $(0.20)$ & $(0.24)$ & $(0.17)$ & $(0.16)$ & $(0.28)$ \\
\hline \multicolumn{7}{|c|}{ Mother's education (Ref=Low) } \\
\hline \multirow[t]{2}{*}{ Medium } & 0.05 & 0.07 & -0.27 & 0.03 & -0.18 & -0.19 \\
\hline & $(0.14)$ & $(0.17)$ & $(0.16)$ & $(0.15)$ & $(0.11)$ & $(0.17)$ \\
\hline \multirow[t]{2}{*}{ High } & 0.23 & 0.01 & -0.66 * & -0.11 & 0.00 & -1.06 \\
\hline & $(0.35)$ & $(0.17)$ & $(0.32)$ & $(0.26)$ & $(0.22)$ & $(0.69)$ \\
\hline \multirow[t]{2}{*}{ Missing } & 0.22 & -0.26 & 0.08 & 0.26 & 0.10 & -0.15 \\
\hline & $(0.32)$ & $(0.29)$ & $(0.33)$ & $(0.23)$ & $(0.19)$ & $(0.44)$ \\
\hline \multicolumn{7}{|c|}{ N. siblings (Ref=None) } \\
\hline \multirow[t]{2}{*}{1 sibling } & -0.09 & 0.21 & 0.22 & 0.19 & 0.10 & -0.03 \\
\hline & $(0.22)$ & $(0.22)$ & $(0.19)$ & $(0.18)$ & $(0.17)$ & $(0.19)$ \\
\hline 2 siblings & -0.03 & 0.34 & 0.49 * & 0.14 & 0.30 & 0.05 \\
\hline & $(0.23)$ & $(0.23)$ & $(0.22)$ & $(0.20)$ & $(0.17)$ & $(0.20)$ \\
\hline $3+$ siblings & 0.13 & 0.39 & 0.38 & 0.44 * & $0.46^{* *}$ & 0.27 \\
\hline & $(0.23)$ & $(0.21)$ & $(0.24)$ & $(0.19)$ & $(0.17)$ & $(0.19)$ \\
\hline SigmaEps & $0.63^{* * *}$ & $0.47^{* * *}$ & $0.83^{* * *}$ & $0.76^{* * *}$ & $0.86^{* * *}$ & $0.83^{* * *}$ \\
\hline & $(0.09)$ & $(0.08)$ & $(0.05)$ & $(0.07)$ & $(0.05)$ & $(0.05)$ \\
\hline In-L & -7030.01 & -6351.97 & -8348.65 & -7729.21 & -18109.19 & -8961.40 \\
\hline
\end{tabular}

Notes: Robust standard errors in parentheses; Significance: ${ }^{\prime * \prime}=5 \%{ }^{\prime{ }^{\prime * * \prime}}=1 \%{ }^{\prime \prime * \star * \prime}=0.1 \%$. 
Table A-2: Effects of control variables for the transition to first and second births, full model (M4), female sample

\begin{tabular}{|c|c|c|c|c|c|c|}
\hline First birth & Austria & Belgium & Bulgaria & Lithuania & Poland & Romania \\
\hline \multicolumn{7}{|c|}{ Splines: Time since graduation } \\
\hline \multirow[t]{2}{*}{ dur0-2 } & $0.29^{* *}$ & $0.44^{* *}$ & 0.06 & -0.07 & $0.20^{* * *}$ & -0.07 \\
\hline & $(0.10)$ & $(0.13)$ & $(0.06)$ & $(0.08)$ & $(0.05)$ & $(0.08)$ \\
\hline \multirow[t]{2}{*}{ dur2-4 } & -0.01 & 0.14 & 0.09 & 0.09 & 0.08 & $-0.13^{*}$ \\
\hline & $(0.07)$ & $(0.08)$ & $(0.05)$ & $(0.07)$ & $(0.04)$ & $(0.06)$ \\
\hline \multirow[t]{2}{*}{ dur4-6 } & 0.13 * & 0.17 * & $-0.23^{* \star \star}$ & -0.09 & -0.09 * & -0.08 \\
\hline & $(0.06)$ & $(0.07)$ & $(0.06)$ & $(0.08)$ & $(0.05)$ & $(0.06)$ \\
\hline \multirow[t]{2}{*}{ dur6-10 } & 0.05 & 0.01 & -0.11 * & -0.08 & -0.08 * & $-0.14^{* *}$ \\
\hline & $(0.03)$ & $(0.04)$ & $(0.05)$ & $(0.05)$ & $(0.03)$ & $(0.04)$ \\
\hline \multirow[t]{2}{*}{ dur10-15 } & $-0.11^{* *}$ & $-0.15^{* *}$ & $-0.16^{* *}$ & -0.15 & -0.07 & $-0.20^{* * *}$ \\
\hline & $(0.04)$ & $(0.05)$ & $(0.06)$ & $(0.08)$ & $(0.04)$ & $(0.06)$ \\
\hline \multirow[t]{2}{*}{ dur15+ } & $-0.21 * *$ & $-0.33^{* * *}$ & -0.18 * & -0.31 & $-0.28^{* * *}$ & $-0.31 * *$ \\
\hline & $(0.07)$ & $(0.09)$ & $(0.09)$ & $(0.18)$ & $(0.06)$ & $(0.11)$ \\
\hline \multirow[t]{2}{*}{ Constant } & $-3.78^{* *}$ & $-8.81^{* \star *}$ & -3.74 * & $-4.33^{*}$ & $-4.69^{* \star *}$ & 1.13 \\
\hline & $(1.34)$ & $(2.24)$ & $(1.73)$ & $(2.05)$ & $(0.98)$ & (1.71) \\
\hline \multicolumn{7}{|l|}{ Cohort (Ref=1970-79) } \\
\hline \multirow[t]{2}{*}{$1960-69$} & 0.16 * & 0.14 & 0.20 ** & 0.21 * & $0.18^{* *}$ & $0.35^{* * *}$ \\
\hline & $(0.07)$ & $(0.08)$ & $(0.07)$ & $(0.10)$ & $(0.07)$ & $(0.08)$ \\
\hline \multirow[t]{2}{*}{$1980-87$} & -0.24 * & -0.30 * & $-0.83^{* \star *}$ & $-0.89^{* \star *}$ & $-0.42^{* \star *}$ & -0.37 * \\
\hline & $(0.10)$ & $(0.13)$ & $(0.13)$ & $(0.18)$ & $(0.07)$ & $(0.16)$ \\
\hline \multirow[t]{2}{*}{ Age at graduation } & -0.02 & 0.31 & 0.16 & 0.23 & 0.19 * & $-0.44^{* *}$ \\
\hline & $(0.12)$ & $(0.20)$ & $(0.16)$ & $(0.19)$ & $(0.09)$ & $(0.16)$ \\
\hline \multirow[t]{2}{*}{ Age at graduation2 } & 0.00 & -0.01 & -0.01 & -0.01 & -0.01 ** & 0.01 * \\
\hline & $(0.00)$ & $(0.00)$ & $(0.00)$ & $(0.00)$ & $(0.00)$ & $(0.00)$ \\
\hline \multicolumn{7}{|c|}{ Father's education (Ref=Low) } \\
\hline \multirow[t]{2}{*}{ Medium } & -0.11 & 0.20 & 0.22 * & 0.05 & -0.15 & 0.01 \\
\hline & $(0.09)$ & $(0.11)$ & $(0.09)$ & $(0.12)$ & $(0.08)$ & $(0.10)$ \\
\hline \multirow[t]{2}{*}{ High } & $-0.46^{* *}$ & 0.01 & 0.16 & 0.07 & $-0.33^{*}$ & 0.22 \\
\hline & $(0.16)$ & $(0.12)$ & $(0.15)$ & $(0.19)$ & $(0.16)$ & $(0.26)$ \\
\hline \multirow[t]{2}{*}{ Missing } & -0.13 & -0.11 & -0.02 & 0.04 & -0.04 & -0.31 \\
\hline & $(0.16)$ & $(0.14)$ & $(0.15)$ & $(0.12)$ & $(0.11)$ & $(0.19)$ \\
\hline \multicolumn{7}{|c|}{ Mother's education (Ref=Low) } \\
\hline \multirow[t]{2}{*}{ Medium } & -0.20 * & -0.11 & -0.26 ** & 0.11 & 0.04 & -0.08 \\
\hline & $(0.08)$ & $(0.10)$ & $(0.10)$ & $(0.11)$ & $(0.08)$ & $(0.11)$ \\
\hline \multirow[t]{2}{*}{ High } & -0.14 & -0.12 & $-0.35^{*}$ & -0.03 & 0.05 & -0.09 \\
\hline & $(0.19)$ & $(0.12)$ & $(0.14)$ & $(0.18)$ & $(0.15)$ & $(0.33)$ \\
\hline \multirow[t]{2}{*}{ Missing } & -0.07 & -0.01 & 0.05 & -0.19 & 0.07 & 0.05 \\
\hline & $(0.22)$ & $(0.19)$ & $(0.22)$ & $(0.20)$ & $(0.16)$ & $(0.22)$ \\
\hline \multicolumn{7}{|c|}{ N.siblings (Ref=None) } \\
\hline \multirow[t]{2}{*}{1 sibling } & 0.15 & 0.11 & -0.06 & -0.05 & 0.12 & 0.19 \\
\hline & $(0.13)$ & $(0.13)$ & $(0.09)$ & $(0.14)$ & $(0.11)$ & $(0.12)$ \\
\hline 2 siblings & 0.29 * & $0.38^{\text {** }}$ & -0.04 & -0.02 & 0.25 * & 0.17 \\
\hline & $(0.14)$ & $(0.14)$ & $(0.12)$ & $(0.15)$ & $(0.12)$ & $(0.13)$ \\
\hline $3+$ siblings & $0.49^{* * *}$ & $0.38^{* *}$ & 0.11 & 0.04 & 0.28 * & 0.20 \\
\hline & $(0.14)$ & $(0.13)$ & $(0.13)$ & $(0.16)$ & $(0.11)$ & $(0.13)$ \\
\hline
\end{tabular}


Trimarchi \& Van Bavel: Gender differences and similarities in the educational gradient in fertility

Table A-2: (Continued)

\begin{tabular}{|c|c|c|c|c|c|c|}
\hline Second birth & Austria & Belgium & Bulgaria & Lithuania & Poland & Romania \\
\hline \multicolumn{7}{|c|}{ Splines: Time since last birth } \\
\hline \multirow[t]{2}{*}{ dur0-2 } & $1.05^{* \star *}$ & $0.96^{* \star \star}$ & $0.68^{* * *}$ & $0.61 * * *$ & $0.52^{* \star \star}$ & $0.29^{* *}$ \\
\hline & $(0.07)$ & $(0.08)$ & $(0.07)$ & $(0.10)$ & $(0.05)$ & $(0.09)$ \\
\hline \multirow[t]{2}{*}{ dur2-4 } & $-0.45^{\star \star *}$ & $-0.39^{* \star *}$ & -0.14 * & $-0.35^{* \star *}$ & -0.09 & -0.12 \\
\hline & $(0.08)$ & $(0.09)$ & $(0.07)$ & $(0.10)$ & $(0.05)$ & $(0.09)$ \\
\hline \multirow[t]{2}{*}{ dur4-6 } & -0.11 & -0.32 * & -0.05 & 0.00 & -0.08 & -0.20 \\
\hline & $(0.10)$ & $(0.13)$ & $(0.08)$ & $(0.12)$ & $(0.06)$ & $(0.11)$ \\
\hline \multirow[t]{2}{*}{ dur6-11 } & -0.10 & -0.14 & $-0.25^{* * *}$ & -0.16 ** & $-0.14^{\star \star \star}$ & $-0.27^{\star \star *}$ \\
\hline & $(0.06)$ & $(0.08)$ & $(0.05)$ & $(0.06)$ & $(0.04)$ & $(0.07)$ \\
\hline \multirow[t]{2}{*}{ dur11+ } & 0.12 & -0.01 & -0.17 & 0.19 & $-0.35^{* \star}$ & -0.10 \\
\hline & $(0.12)$ & $(0.18)$ & $(0.14)$ & $(0.11)$ & $(0.12)$ & $(0.17)$ \\
\hline \multirow[t]{2}{*}{ Constant } & $-4.95^{* \star *}$ & -5.61 ** & $-5.05^{* *}$ & $-4.18^{*}$ & $-6.41^{* \star \star}$ & -0.42 \\
\hline & $(1.36)$ & $(1.93)$ & $(1.69)$ & $(1.92)$ & $(1.26)$ & $(1.88)$ \\
\hline \multicolumn{7}{|c|}{ Cohort (Ref=1970-1979) } \\
\hline \multirow[t]{2}{*}{ 1960-1969 } & -0.05 & 0.08 & $0.48^{* * *}$ & $0.50^{* * *}$ & $0.25^{\star \star \star}$ & 0.15 \\
\hline & $(0.09)$ & $(0.10)$ & $(0.09)$ & $(0.13)$ & $(0.07)$ & $(0.10)$ \\
\hline \multirow[t]{2}{*}{$1980-1987$} & -0.35 * & $-0.67^{* *}$ & $-0.75^{*}$ & -0.38 & $-0.28 * \star$ & -0.55 \\
\hline & $(0.17)$ & $(0.24)$ & $(0.31)$ & $(0.40)$ & $(0.11)$ & $(0.37)$ \\
\hline \multirow[t]{2}{*}{ Age at first birth } & 0.01 & 0.09 & 0.05 & -0.07 & 0.21 * & -0.14 \\
\hline & $(0.10)$ & $(0.13)$ & $(0.14)$ & $(0.14)$ & $(0.10)$ & $(0.15)$ \\
\hline \multirow[t]{2}{*}{ Age at first birth2 } & 0.00 & 0.00 & 0.00 & 0.00 & 0.00 * & 0.00 \\
\hline & $(0.00)$ & $(0.00)$ & $(0.00)$ & $(0.00)$ & $(0.00)$ & $(0.00)$ \\
\hline \multicolumn{7}{|c|}{ Father's education (Ref=Low) } \\
\hline \multirow[t]{2}{*}{ Medium } & 0.07 & 0.17 & $-0.36^{* *}$ & 0.12 & $-0.21 *$ & -0.18 \\
\hline & $(0.10)$ & $(0.13)$ & $(0.12)$ & $(0.16)$ & $(0.09)$ & $(0.12)$ \\
\hline \multirow[t]{2}{*}{ High } & 0.20 & -0.06 & -0.02 & 0.43 & $-0.46^{*}$ & -0.71 \\
\hline & $(0.20)$ & $(0.15)$ & $(0.19)$ & $(0.25)$ & $(0.21)$ & $(0.44)$ \\
\hline \multirow[t]{2}{*}{ Missing } & -0.15 & -0.23 & -0.13 & 0.09 & -0.15 & -0.45 \\
\hline & $(0.20)$ & $(0.19)$ & $(0.19)$ & $(0.17)$ & $(0.13)$ & $(0.29)$ \\
\hline \multicolumn{7}{|c|}{ Mother's education (Ref=Low) } \\
\hline \multirow[t]{2}{*}{ Medium } & 0.02 & 0.15 & $-0.31^{\star \star}$ & -0.19 & -0.06 & -0.20 \\
\hline & $(0.10)$ & $(0.12)$ & $(0.11)$ & $(0.15)$ & $(0.09)$ & $(0.15)$ \\
\hline \multirow[t]{2}{*}{ High } & -0.34 & 0.14 & -0.44 * & -0.19 & -0.04 & 0.70 \\
\hline & $(0.25)$ & $(0.16)$ & $(0.20)$ & $(0.24)$ & $(0.21)$ & $(0.44)$ \\
\hline \multirow[t]{2}{*}{ Missing } & -0.29 & 0.50 * & 0.08 & -0.15 & -0.04 & 0.22 \\
\hline & $(0.29)$ & $(0.20)$ & $(0.28)$ & $(0.25)$ & $(0.18)$ & $(0.35)$ \\
\hline \multicolumn{7}{|c|}{ N. siblings (Ref=None) } \\
\hline \multirow[t]{2}{*}{1 sibling } & 0.03 & 0.49 ** & 0.06 & 0.10 & 0.20 & 0.19 \\
\hline & $(0.20)$ & $(0.19)$ & $(0.13)$ & $(0.18)$ & $(0.16)$ & $(0.18)$ \\
\hline 2 siblings & 0.50 * & $0.55^{\text {** }}$ & 0.25 & 0.15 & $0.47^{* *}$ & 0.19 \\
\hline & $(0.20)$ & $(0.19)$ & $(0.16)$ & $(0.19)$ & $(0.16)$ & $(0.18)$ \\
\hline $3+$ siblings & 0.51 ** & $0.67^{\star \star * *}$ & 0.13 & $0.60^{* *}$ & $0.57^{* * *}$ & 0.38 * \\
\hline & $(0.20)$ & $(0.19)$ & $(0.17)$ & $(0.20)$ & $(0.15)$ & $(0.18)$ \\
\hline SigmaEps & $0.57^{* * *}$ & $0.55^{\star * \star}$ & $0.68^{\star \star \star}$ & $0.80^{* \star *}$ & $0.87^{\star \star \star}$ & NA \\
\hline & $(0.08)$ & $(0.07)$ & $(0.04)$ & $(0.06)$ & $(0.04)$ & \\
\hline In-L & -12814.95 & -9049.65 & -13138.90 & -8347.09 & -23802.36 & -8221.41 \\
\hline
\end{tabular}

Notes: Robust standard errors in parentheses; Significance: ${ }^{* * \prime}=5 \%{ }^{\prime * * \prime \prime}=1 \%$; ${ }^{\prime * * * \prime}=0.1 \%$. 